\title{
Experimental Study on Seismic Performance of Fabricated Steel Foamed Concrete T-Shaped Wallboard
}

\author{
Ding Zhou, Dianzhong Liu (D, and Kuolin Li \\ College of Civil Engineering, Jilin Jianzhu University, Changchun 130000, Jilin, China \\ Correspondence should be addressed to Dianzhong Liu; dz105@163.com
}

Received 21 April 2020; Revised 29 October 2020; Accepted 28 November 2020; Published 18 December 2020

Academic Editor: Wenbing Wu

Copyright (c) 2020 Ding Zhou et al. This is an open access article distributed under the Creative Commons Attribution License, which permits unrestricted use, distribution, and reproduction in any medium, provided the original work is properly cited.

\begin{abstract}
At the present stage, some research results have been made on connection of joints of fabricated reinforced concrete wallboards in China, but there is little research on the connection methods of steel-concrete composite structure, or methods like welding are directly adopted. On the basis of previous studies, a new type of joint connection method for steel-concrete composite structure was proposed. Self-tapping nails are used to connect the steel frames in the wallboard, and this joint connection method is used to splice the web and the flange plate. Concrete postcast strip was set up to produce the fabricated T-shaped wallboard specimens, and the failure form, bearing capacity characteristics, strain condition, wall displacement, and seismic performance were studied and analyzed, which provided data support for theoretical research. ABAQUS finite element software was used to establish an overall structure model, and the theoretical data and experimental data were obtained through simulation for comparative analysis in which the failure form, bearing capacity characteristics, strain condition, wall displacement, and seismic performance were compared to verify the reliability of the experiment.
\end{abstract}

\section{Introduction}

Prefabricated buildings represent the needs and goals of the construction industry in the future, and meanwhile prefabricated steel foamed concrete structures [1-3] have advantages such as light weight, high strength, and green and environmental protection [4], which not only adapt to the development of modern architecture but also meet the rigid demand of buildings in the future on structures. At the same time, the steel-concrete composite structure has advantages of high bearing capacity $[5,6]$, fast construction speed, and stable performance, which make it unique in the construction industry and widely recognized and applied. At present, studies on joints of beams and columns in composite structures in China are relatively thorough, but researches related to wallboard and wallboard joints are relatively shallow. In the past, welding was often used, which was time-consuming and laborious. Therefore, under the current background of the proceeding of research on prefabricated structure with great enthusiasm in China, a new joint connection method is proposed on the basis of its own advantages and characteristics, and the reliability of this method is obtained through experiments and simulations. The research of this topic provides new ideas and scientific basis for the research and development of the connection of subsequent composite structural boards and is of great significance for enriching and perfecting its theoretical system [7]. In the experiment, the two-side light steel light concrete T-shaped composite wallboard was designed. Each composite wallboard was assembled with two prefabricated wallboards of the same material, shape, and size but with different spaces between steels. A quasi-static failure test was performed on two T-shaped walls to observe the rule of crack development and the failure phenomenon and to study its bearing capacity, ductility, deformation ability, joint failure characteristics, and so forth.

\section{Test Design and Test Method of Prefabricated T-Shaped Composite Wall}

2.1. Test Content and Significance. This test was an innovative test with two specimens. Each specimen was assembled with two prefabricated wallboards of the same material, shape, and size but with different spaces between steels. A quasi- 
static failure test was performed on two T-shaped walls to observe the rule of crack development and the failure phenomenon, study its bearing capacity, ductility, deformation ability, joint failure characteristics, and the like, and compare and analyze the simulation results of the finite element analysis software ABAQUS. The description of main work is as follows:

(1) The mechanical properties of the materials, foamed concrete, and light steel used in the test were tested to obtain the data

(2) The test members shall be cast, maintained, assembled, recast, and then hoisted to the designated test site by a crane for test loading after the completion of the secondary maintenance

(3) Under the action of low-cycle reciprocating loads, the seismic performances of the test specimens such as ultimate load and yield load were studied

(4) During the test, a hydraulic servo control system was used to collect the data of loads and displacements, and the strain gauges affixed to the surface of foamed concrete and light steel were used to collect the strain data for later theoretical analysis

Under the current background of the proceeding of research on prefabricated structure with great enthusiasm in China, a new joint connection method is proposed on the basis of its own advantages and characteristics, and the reliability of this method is obtained through experiments and simulations. The research provides new ideas and scientific basis for the research and development of the connection of subsequent composite structural boards and is of great significance for enriching and perfecting its theoretical system.

2.2. Raw Materials. The foamed concrete used in this test consists of ordinary Portland cement, fly ash, foaming agent, and water. The foamed concrete fly ash produced in the test accounted for $20 \%$ of the total dry powder. The second casting part is mixed with expansion agent to ensure a tight connection with the first casting part. Tables $1-3$ are the mix ratio [8] for preparing $1 \mathrm{~m}^{3}$ of the foamed concrete with a density of $1600 \mathrm{~kg} / \mathrm{m}^{3}$, its mechanical properties, and the mechanical properties of the cold-formed thin-walled steel [9].

2.3. Sizes of Specimens. Two test specimens were made in the test, and the cross sections of the specimens were both $\mathrm{T}$-shaped. The space between steels being $150 \mathrm{~mm}$ was indicated by $\mathrm{T}-1$ and that being $200 \mathrm{~mm}$ was indicated by $\mathrm{T}-2$, with the factor of coupling beam being not considered.

In view of the characteristics of the composite structure of light steel-foamed concrete, a new connection method was proposed to connect relevant joints. The steel at the joint of the flange plate was wrapped around the steel at the joint of the web, and then self-tapping screws were driven in from the side to combine the steel frames of different types of wallboards $[10,11]$, as shown in Figures 1 and 2.
The section height of the wall is $1250 \mathrm{~mm}$ and the section thickness is $150 \mathrm{~mm}$. The length of the flange wall is $1350 \mathrm{~mm}$, and the flange thickness is $150 \mathrm{~mm}$. The height of the wall is $2800 \mathrm{~mm}$.

The members of the specimen are divided into flange plate and web, both of which adopt C100 $\times 50 \times 2 \times 2.5 \mathrm{~mm}$ cold-formed thin-walled steel as the main body. A single piece of $\mathrm{C} 100 \times 80 \times 2 \times 2.5 \mathrm{~mm}$ special steel is used at the web joint. At the joint of flange plates, two pieces of $\mathrm{C} 110 \times 50 \times 2 \times 2.5 \mathrm{~mm}$ special steel are placed side by side. The $50 \mathrm{~mm} \times 2 \mathrm{~mm}$ flat steels are used as the transverse and oblique ties, which are connected together by self-tapping screws to form a steel frame, and the steel frame is built in and then casted [12].

The sectional dimension of the loading beam is $200 \mathrm{~mm} \times 400 \mathrm{~mm}$, and the corresponding length of the web is $1350 \mathrm{~mm}$. The corresponding length of flange is $1650 \mathrm{~mm}$. The sectional dimension of the bottom beam is $400 \mathrm{~mm} \times 400 \mathrm{~mm}$ and the length of the flange is $2200 \mathrm{~mm}$, as shown in Figures 3-6.

\subsection{Layout of Measuring Points}

(1) Displacement meters: displacement meters are placed on the flange plate at $200 \mathrm{~mm}$ from the top, 1/ 2 and 1/4 from the top, and $200 \mathrm{~mm}$ from the wall bottom, on the center of mudsill corresponding to the flange plate and on the center of the web plate, as detailed in Figure 7.

(2) Section steel strain gauges: in this test, some measuring points are required to measure the strain of channel steel in the steel skeleton corresponding to the wall, special channel steel at the joint position, transverse flat steel, and oblique flat steel, as detailed in Figure 8.

(3) Foam concrete strain: strain gauges are arranged at the corresponding positions on the front and back sides of the flange plate and the corresponding position on one side of the web plate, as detailed in Figure 9.

2.5. Test Loading Scheme. In this test, the method of quasistatic test is adopted. Firstly, the vertical load is applied and the load value is kept constant in the test. In the horizontal direction, a low-cycle reciprocating load is applied to the specimen until the specimen is broken.

2.5.1. Vertical Loading. There are two T-shaped wallboards in this structure test, and the axial pressure ratios of the two specimens are both 0.3 . Before the test, calculate the position of the centroid of the T-shaped wallboard to determine the loading position of the vertical load. Before the test, preload the specimen to ensure that all parts of the specimen are in close contact. In this way, the operator can also observe the working condition and performance of each instrument. The preloading value is $40 \%$ of the full load, and the loading 
TABLE 1: Mixing ratio of foamed concrete.

\begin{tabular}{lcccccc}
\hline $\begin{array}{l}\text { Expanding agent } \\
\mathrm{kg}\end{array}$ & $\begin{array}{c}\text { Fly ash } \\
\mathrm{kg}\end{array}$ & $\begin{array}{c}\text { Cement } \\
\mathrm{kg}\end{array}$ & $\begin{array}{c}\text { Water } \\
\mathrm{kg}\end{array}$ & $\begin{array}{c}\text { Foam } \\
\mathrm{kg}\end{array}$ & $\begin{array}{c}\text { Foam water } \\
\mathrm{kg}\end{array}$ & $\begin{array}{c}\text { Foaming agent } \\
\mathrm{kg}\end{array}$ \\
\hline 0 & 200 & 800 & 400 & 0.735 & 10.81 & 0.42 \\
\hline
\end{tabular}

TABLE 2: Mechanical properties of cold-formed thin-walled steel.

\begin{tabular}{lcccccc}
\hline Specimen number & 1 & 2 & 3 & 4 & 5 & Average value \\
\hline Yield strength $(\mathrm{MPa})$ & 304 & 328 & 379 & 352 & 349 & 342.4 \\
Ultimate strength $(\mathrm{MPa})$ & 475 & 505 & 521 & 493 & 491 & 497 \\
\hline
\end{tabular}

TABle 3: Strength of foamed concrete specimens.

\begin{tabular}{lcccc}
\hline Specimen number & 1 & 2 & 3 & Average value \\
\hline Measured density $\left(\mathrm{kg} / \mathrm{m}^{3}\right)$ & 1699.26 & 1699.26 & 1650.37 & 1682.96 \\
Compressive strength $(\mathrm{MPa})$ & 29.16 & 32.06 & 27.17 & 29.46 \\
\hline
\end{tabular}

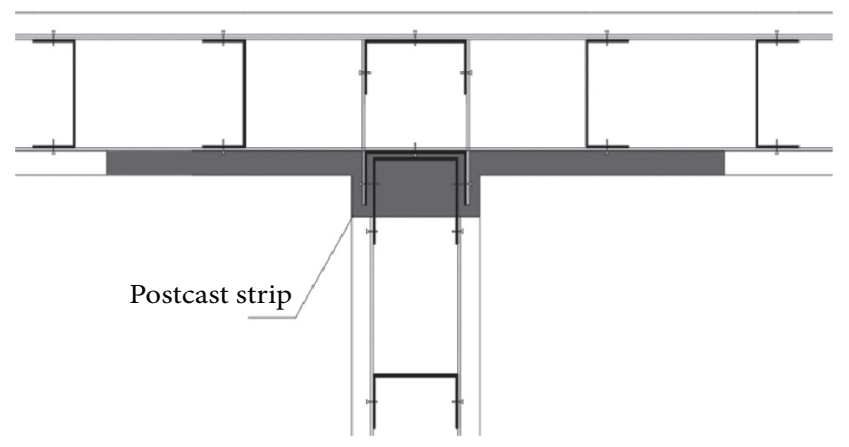

FIgURE 1: T-type wallboard joints.

(unloading) is repeated 3 times, and then load to $100 \%$ of the full load and the load value is kept constant during the test.

2.5.2. Horizontal Loading. In order to ensure the coherence of the test and the accuracy of the results, the equal-amplitude loading system [13] in the controlled displacement loading method is adopted.

It is shown in Figure 10.

2.6. Test Loading Equipment. For vertical loading, Hangzhou POPWIL hydraulic jack with a maximum range of $2000 \mathrm{kN}$ is adopted. During the test, the jack is connected to the steel plate with a screw rod. Meanwhile, the connection between the jack and the reaction beam is provided with a sliding track so that the jack can slide forward and backward [14]. In this way, when horizontal displacement occurs in the specimen, the jack can always act on the centroid without deviation. Hangzhou POPWIL hydraulic jack with a maximum range of $1000 \mathrm{kN}$ is adopted as the horizontal loading equipment. During the test, the actuator and the connector are connected with bolts, and 4 screws are inserted into the circular holes reserved in advance in the loading beam and fixed with steel plates and nuts, with the other end being bolted with the connecting piece. Fixed beams are placed at three positions where T-shaped ground beams are protruding from the wallboard and are fixed with anchor bolts to ensure that the specimen does not shift and rotate under the horizontal load. It is shown in Figure 11.

\section{Test Results and Analysis}

3.1. Test Process and Failure Phenomenon. The density of foamed concrete in T-1 specimen was $1600 \mathrm{~kg} / \mathrm{m}$, and the space between steels was $150 \mathrm{~mm}$. During the test, the direction of the forward thrust displacement exerted by the jack was positive, and the direction of the backward thrust displacement was negative. At first, the specimen was subjected to axial pressure. When the axial pressure was increased to a constant value, a horizontal displacement was applied. When the positive loading displacement was $8 \mathrm{~mm}$ and the load was $36.8 \mathrm{kN}$, the web gave out a slight cracking sound and vertical cracks appeared; when the displacement reached $16 \mathrm{~mm}$ and the load was $48 \mathrm{kN}$, obvious crackles occurred and the protective layer of the postcast strip was partially peeled off; when the displacement reached $-18 \mathrm{~mm}$ and the load was $-142.6 \mathrm{kN}$, the protective layer on the left side of the web was damaged, the oblique flat steel buckled, and the buckling part of the left oblique flat steel was exposed; when the displacement reached $-22 \mathrm{~mm}$ and the load was $-174.7 \mathrm{kN}$, the specimen produced low and deep "doh" sounds and the concrete protective layer on the left side of the web peeled off more seriously; when the displacement reached $26 \mathrm{~mm}$ and the load was $53.9 \mathrm{kN}$, the protective layer on the right side peeled off and the oblique flat steel on the right side buckled; as the test went on, the horizontal displacement increased, the concrete on both sides of the web was peeling off more and more seriously, and the cracks in the contact part of the two casts were increasing, forming cold joints and finally being separated; when the displacement reached $45 \mathrm{~mm}$, a large area of concrete on both sides of the web peeled off, most steel of the web was exposed, and the oblique flat steel on both 


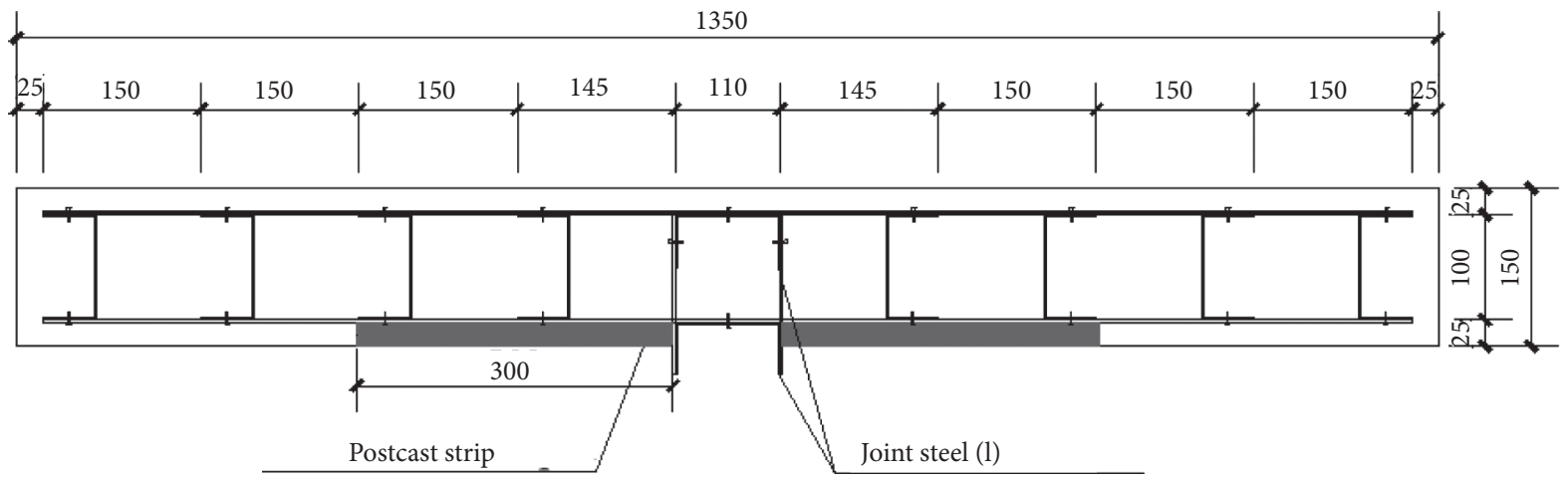

(a)

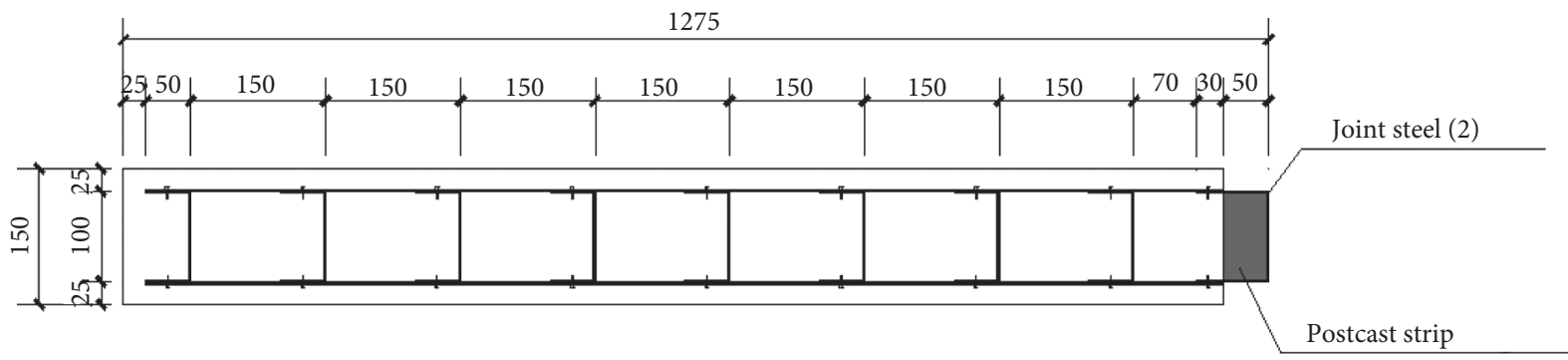

(b)
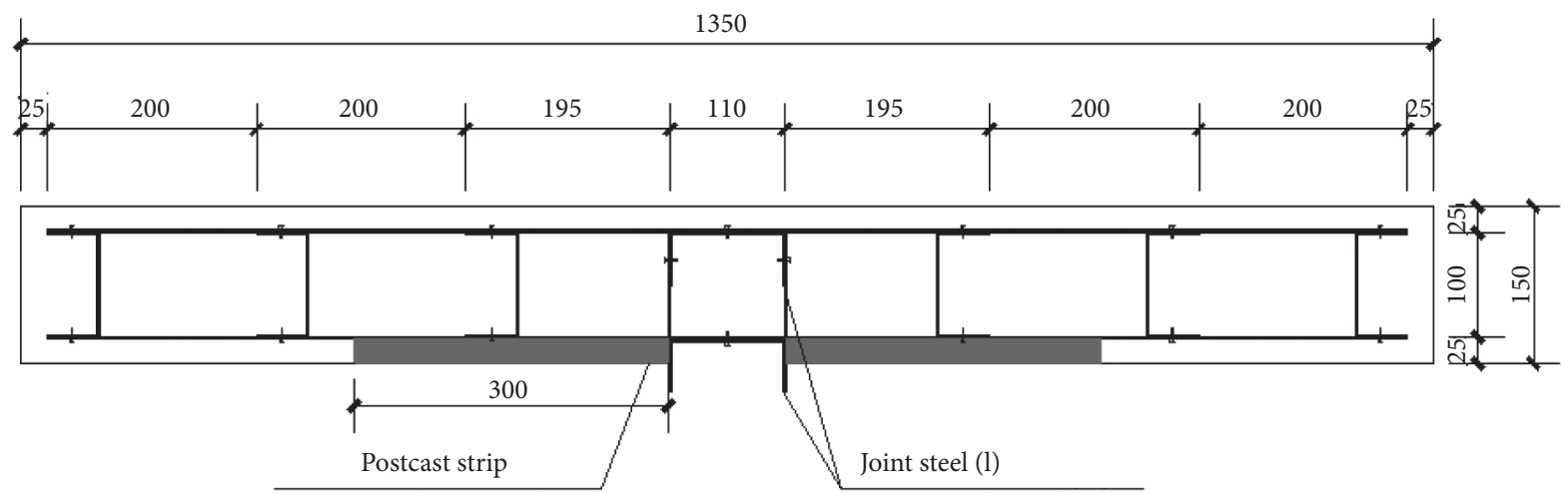

(c)

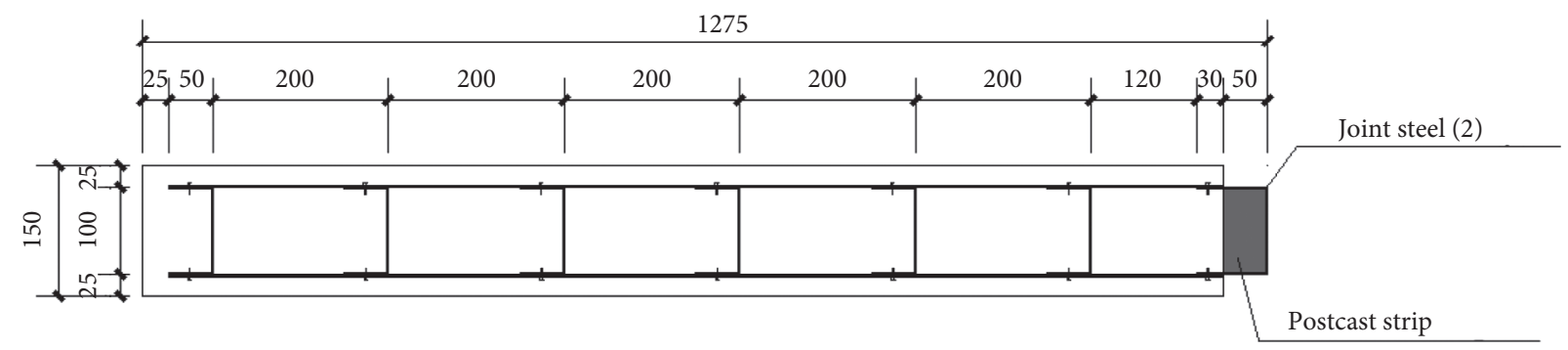

(d)

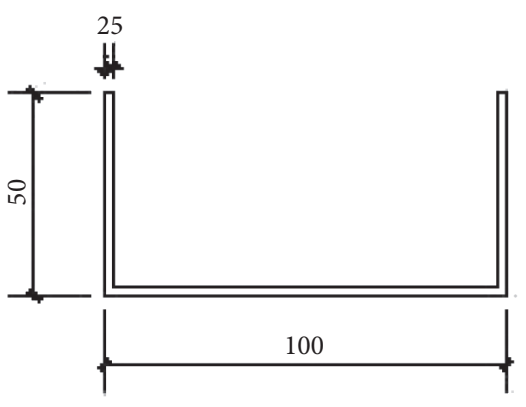

(e)

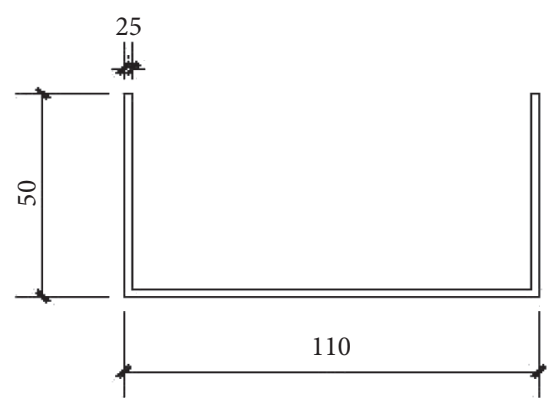

(f)

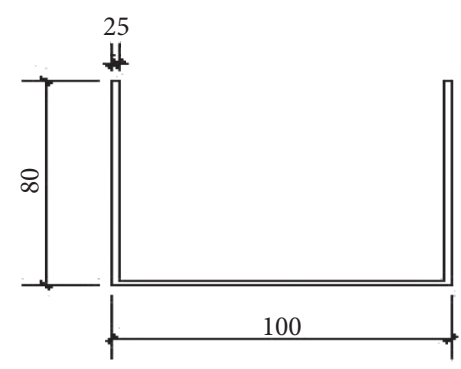

(g)

Figure 2: Size diagram of assembly wallboard. (a) Flange with steel space of $150 \mathrm{~mm}$. (b) Web with steel space of $150 \mathrm{~mm}$. (c) Flange with steel space of $200 \mathrm{~mm}$. (d) Web with steel space of $200 \mathrm{~mm}$. (e) Ordinary steel. (f) Joint steel 1. (g) Joint steel 2. 


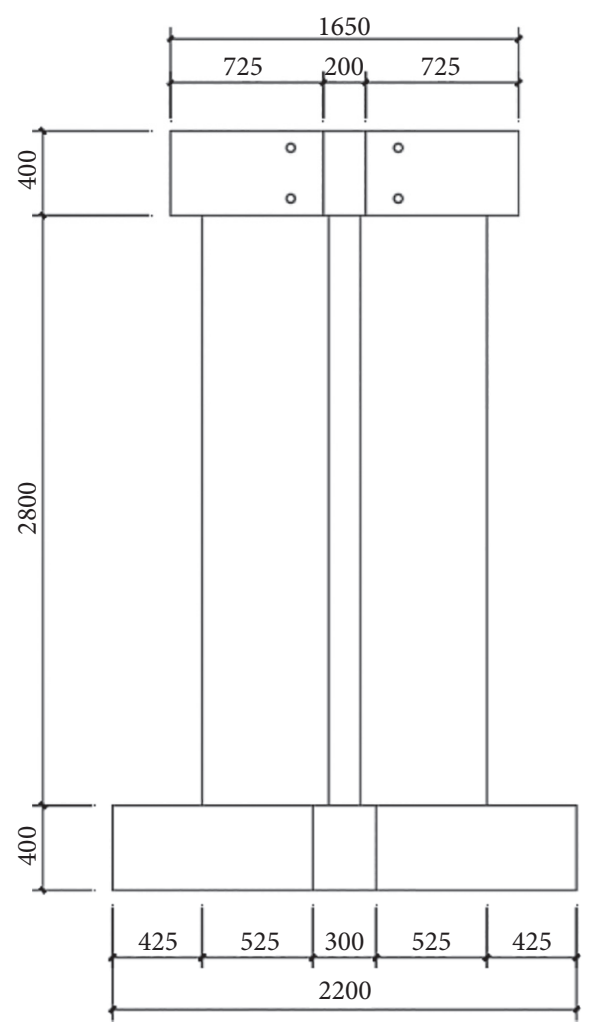

(a)

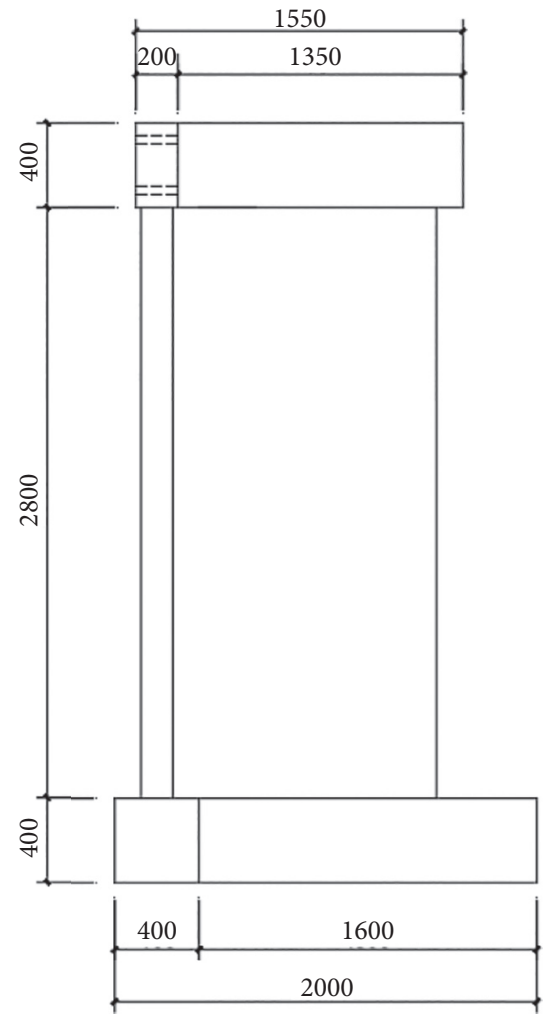

(b)

FIgURE 3: Overall model.

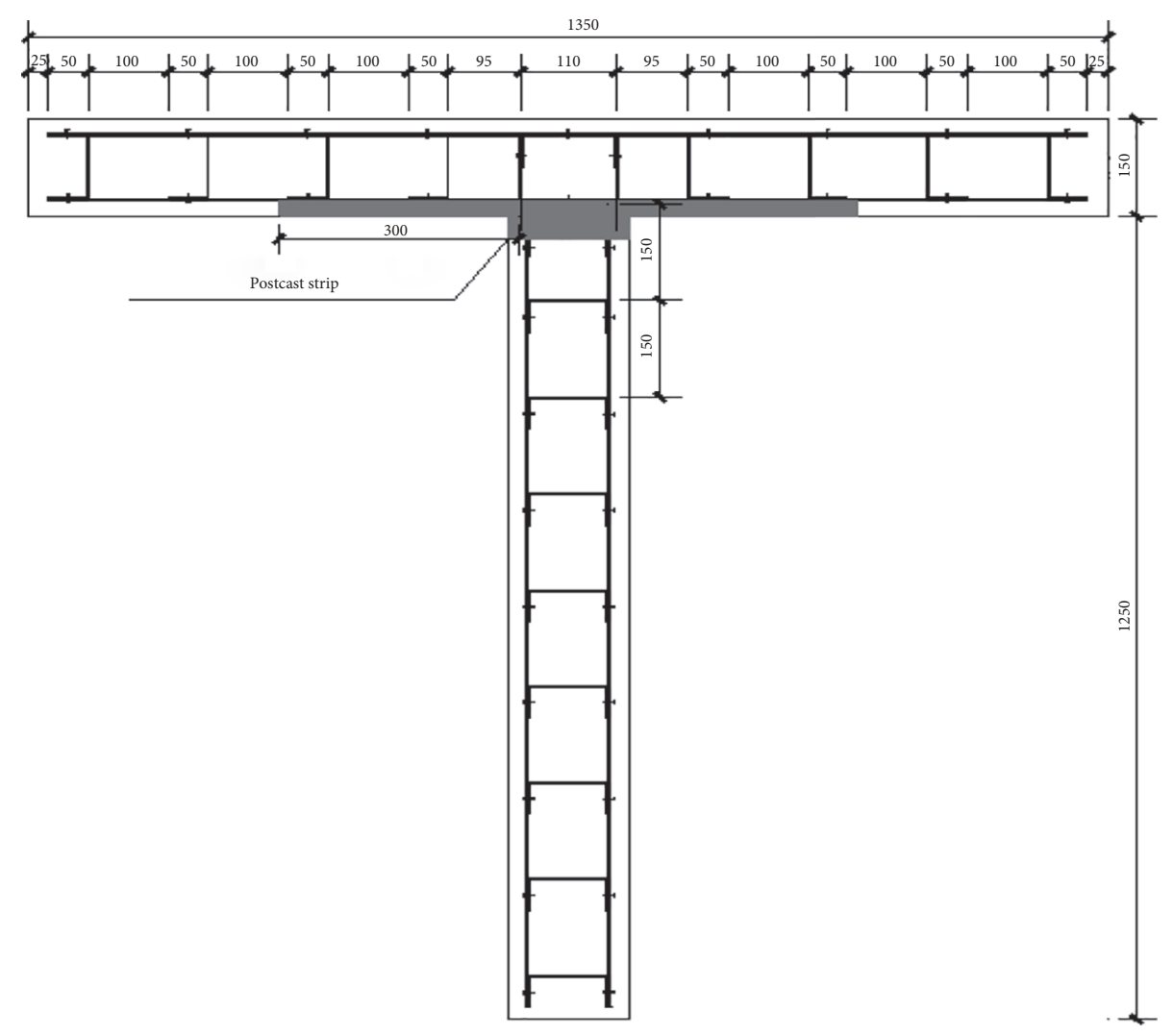

FIgURE 4: Wallboard size diagram of T-1. 


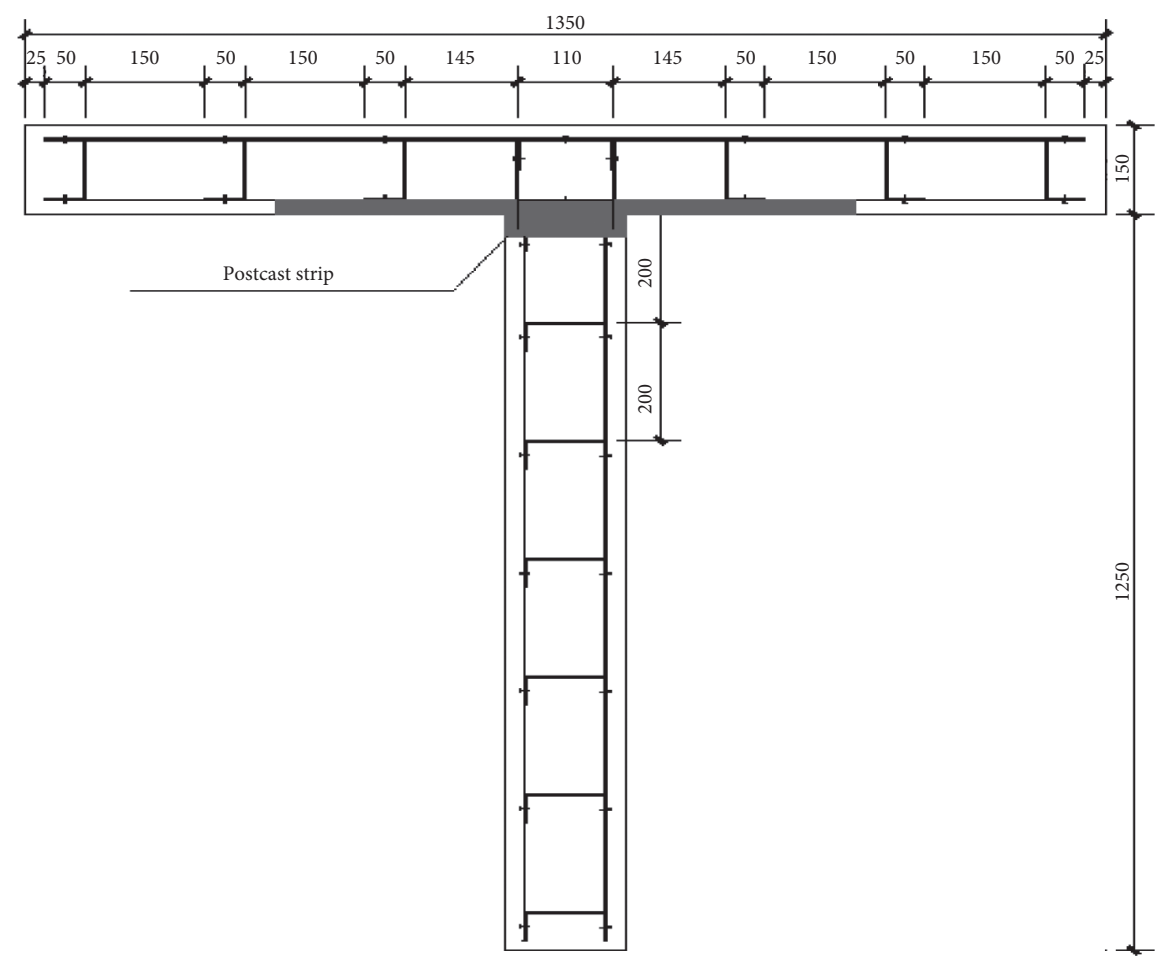

Figure 5: Wallboard size diagram of T-2.

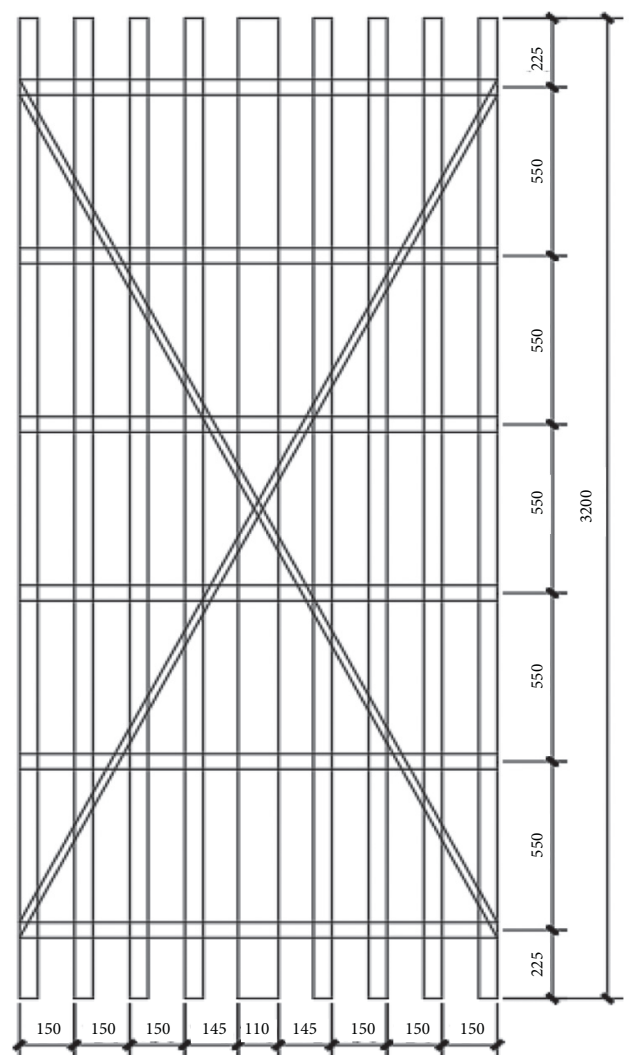

(a)

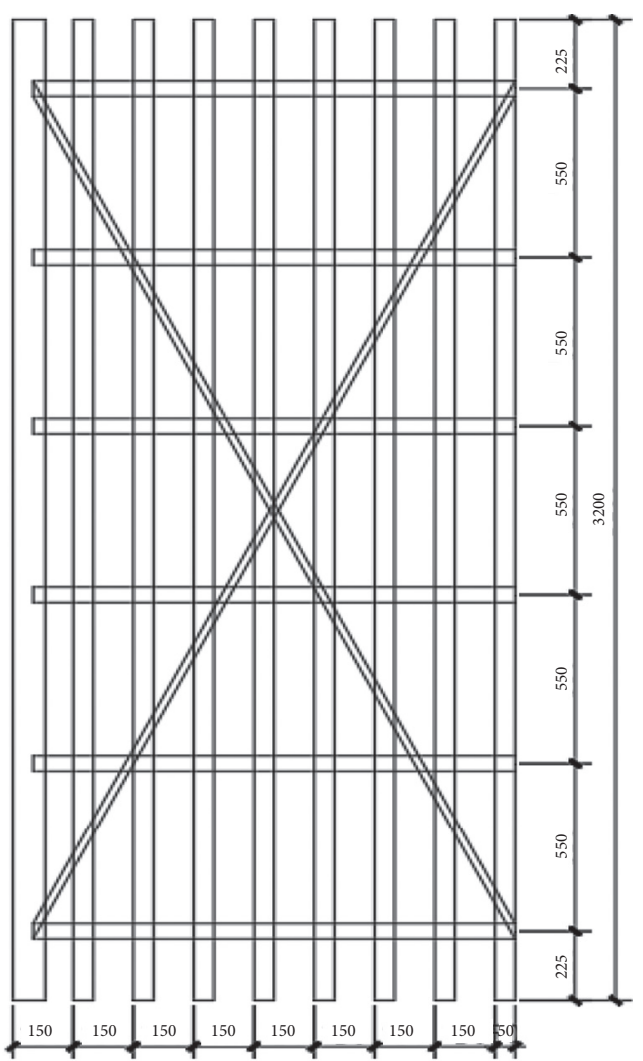

(b)

Figure 6: Continued. 


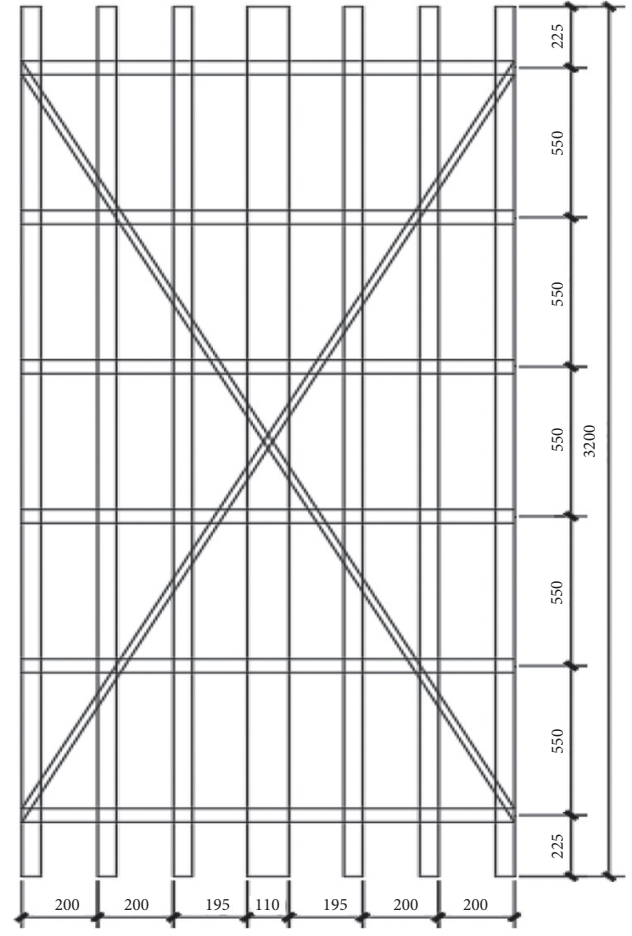

(c)

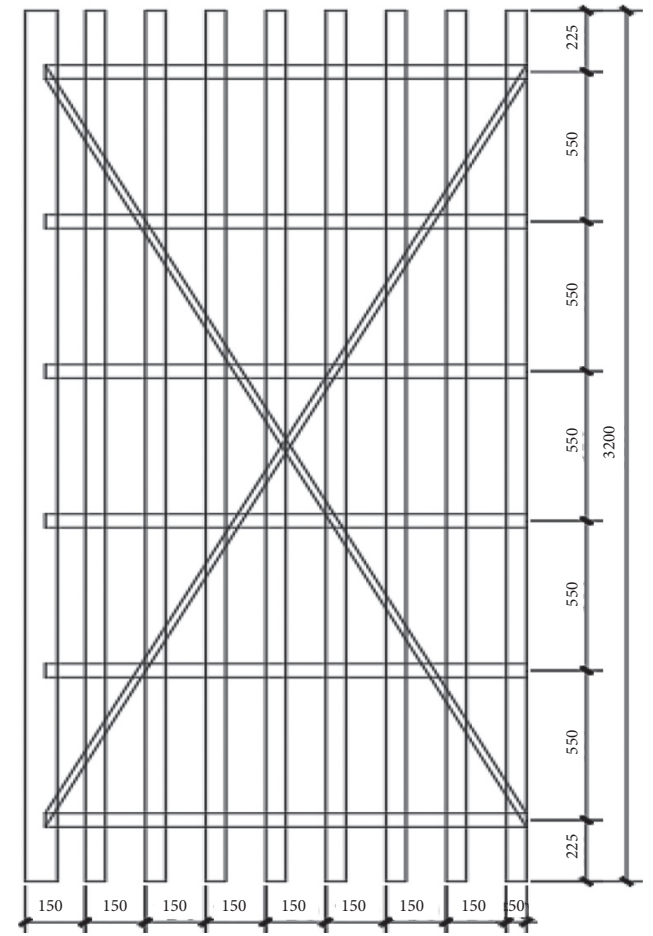

(d)

Figure 6: Size of steel frame. (a) Flange with a space of $150 \mathrm{~mm}$. (b) Web with a space of $150 \mathrm{~mm}$. (c) Flange with a space of $200 \mathrm{~mm}$. (d) Web with a space of $200 \mathrm{~mm}$.

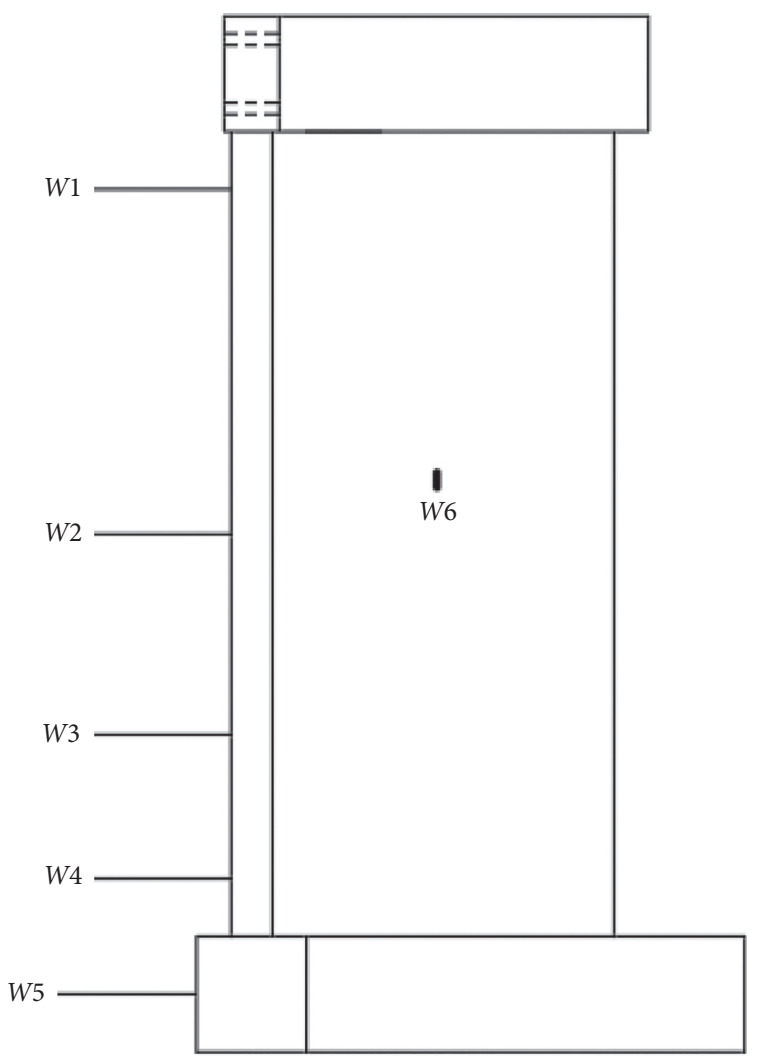

FIGURE 7: Displacement meter position. 


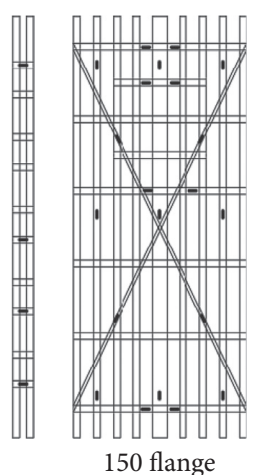

(a)

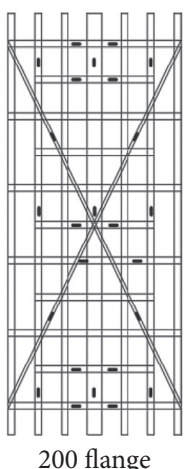

(c)

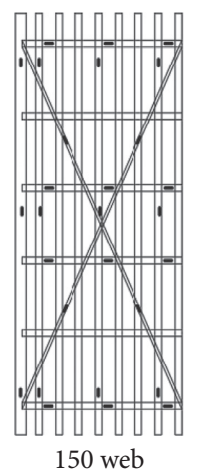

(d)

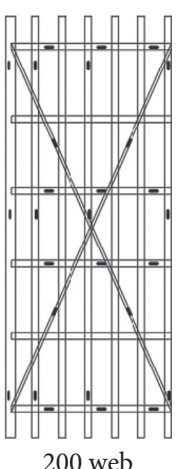

(e)

Figure 8: Layout of strain gauges for section steel.

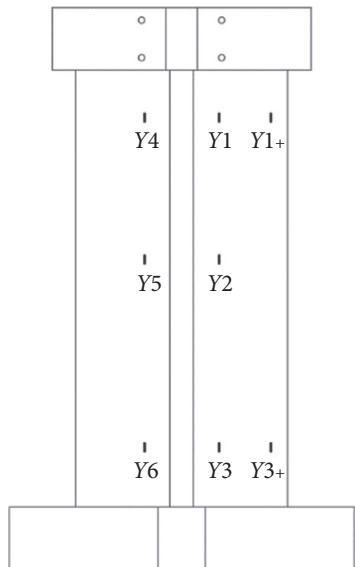

(a)

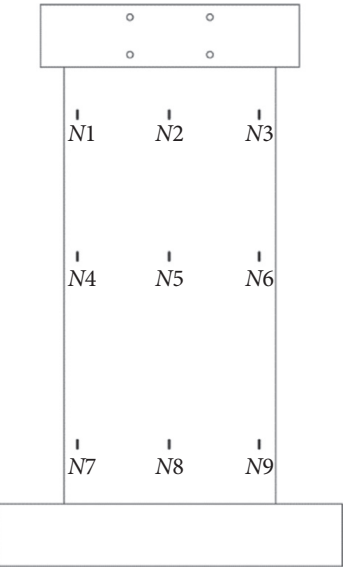

(b)

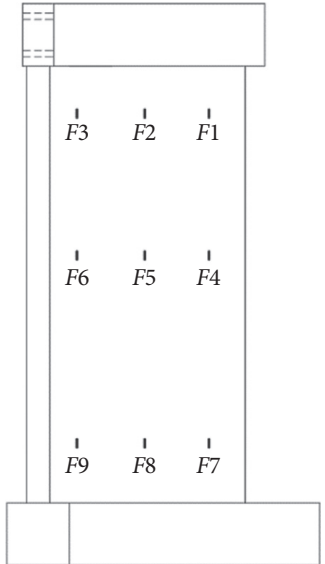

(c)

FIgURE 9: Layout of strain gauge for foam concrete.

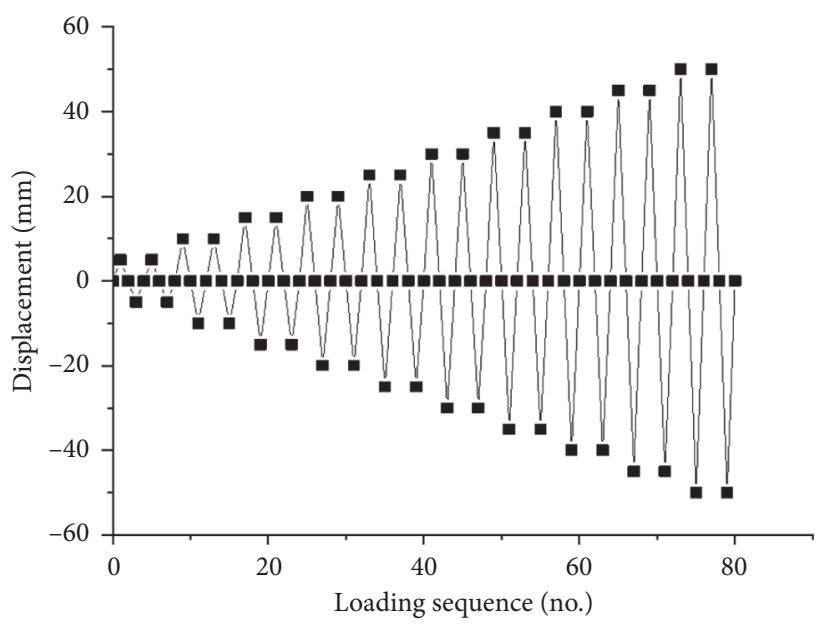

FIgURE 10: Control loading curve of specimens.

sides buckled significantly, and most of them were also exposed. The test stopped. The test process and failure phenomenon are shown in Figures 12-15.

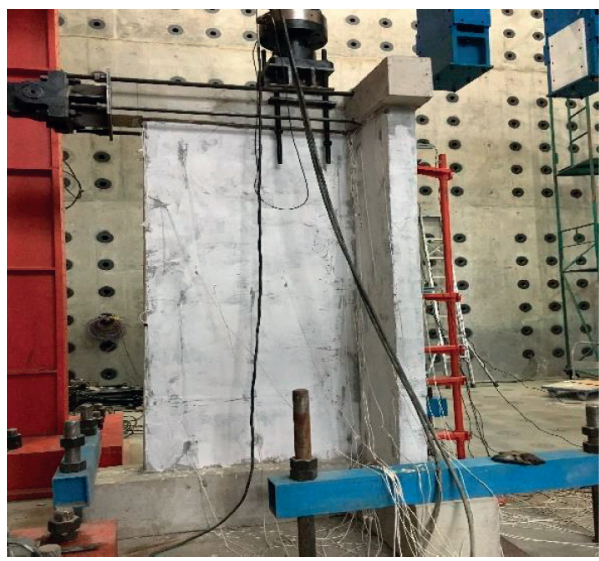

Figure 11: Test entirety.

When the T-2 specimen was subjected to vertical load, the axial pressure was increased to a constant value, and a horizontal displacement was applied. During the test, the direction of the forward thrust displacement exerted by the jack was positive, and the direction of the backward thrust 


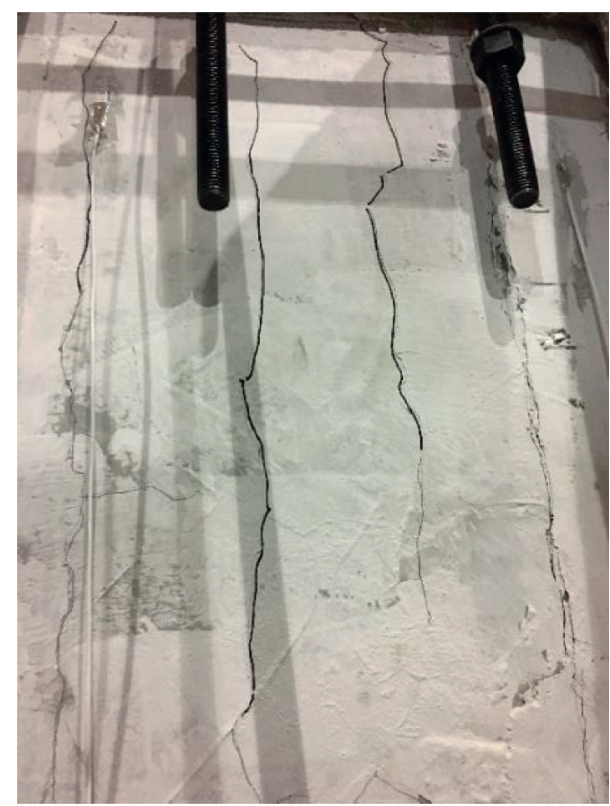

Figure 12: Fracture development.

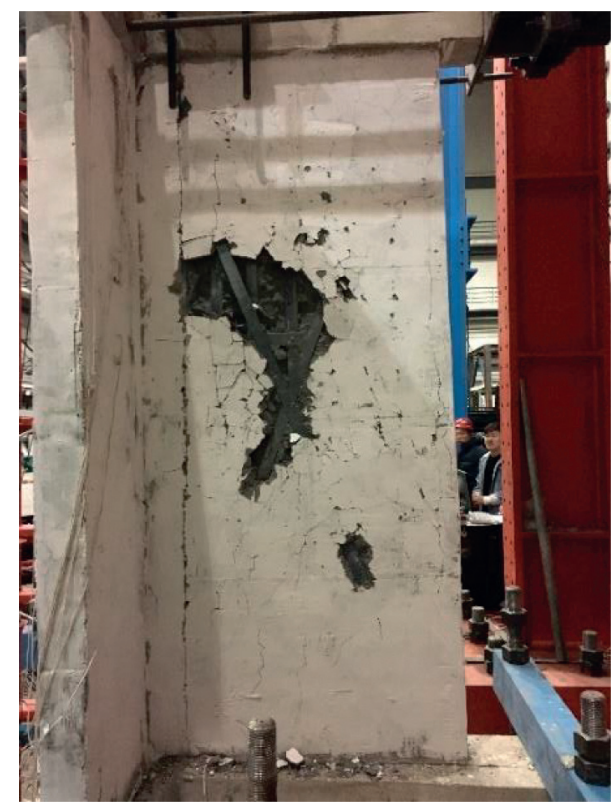

Figure 13: Buckling of oblique section steel.

displacement was negative. When the horizontal displacement reached $8 \mathrm{~mm}$, the horizontal load was $72.9 \mathrm{kN}$, and a slight cracking sound was produced; when the displacement reached $12 \mathrm{~mm}$ and the load was $75.2 \mathrm{kN}$, cracks appeared on the right side of the web with the cracking sound, the original cracks on the specimen before the test extended slightly, and the lateral cracks on the web appeared; when the displacement reached $14.1 \mathrm{~mm}$ and the load was $78 \mathrm{kN}$, a small piece of concrete on the right side of the web protruded outward and cracked, with a small piece of oblique flat steel being exposed and oblique flat steel being buckled; when the displacement reached $-17 \mathrm{~mm}$ and the load was $-155.1 \mathrm{kN}$,

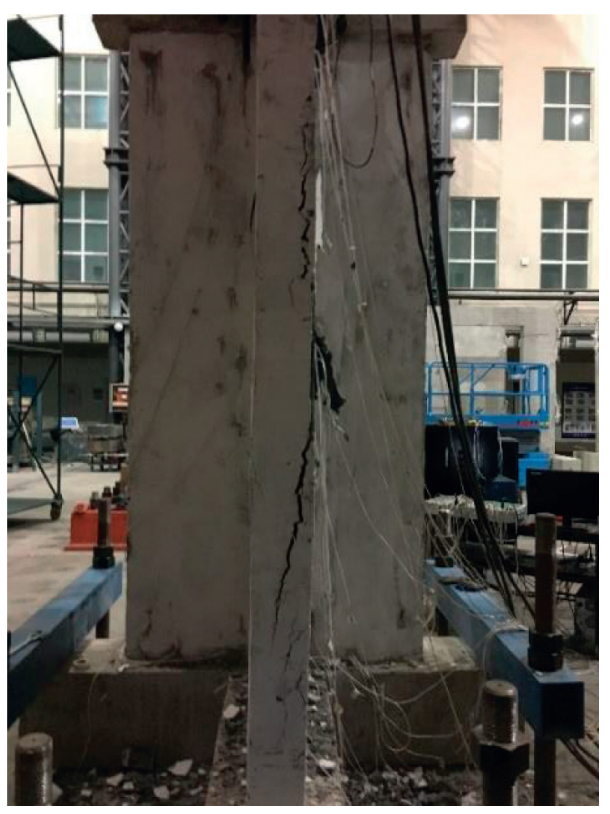

FIGURE 14: Lateral web cracks.

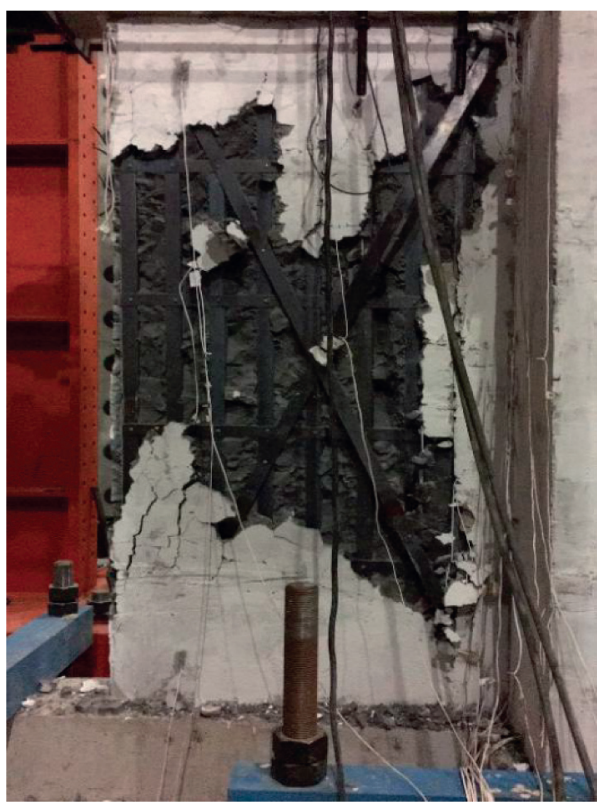

Figure 15: Final failure patterns.

the crackles were intensive, the web cracks increased, and there were fine cracks in the contact part of the two casts; when the displacement reached $-20 \mathrm{~mm}$, the load was $-170.4 \mathrm{kN}$, and a small part of the concrete protective layer on the left side of the web peeled off, with the oblique flat steel being exposed and buckled; when the displacement reached $-23 \mathrm{~mm}$ and the load was $-188.4 \mathrm{kN}$, the concrete corresponding to the other flat steel on the right peeled off and the flat steel buckled; when the displacement reached $24.2 \mathrm{~mm}$ and the load was $71.1 \mathrm{kN}$, cracks appeared at the bottom of the web and the shapes of cracks on the side increased; as the test progressed, the cracks on the east and 
west sides of the web increased, and the cracks appeared mostly in the corresponding positions of the steel, with cracks at the bottom being more obvious and those on the sides being more and larger; when the displacement reached $-32 \mathrm{~mm}$ and the load was $-183.5 \mathrm{kN}$, the specimen produced intensive crackles and made low and deep "doh" sounds and the self-tapping nail fractured at the intersection of flat steel on the east side of the web, with the concrete peeling off more seriously; when the displacement reached $40 \mathrm{~mm}$, a large area of concrete on both sides of the web peeled off and most steels were exposed. The test stopped. The test process and failure phenomenon are shown in Figures 16-19.

3.2. Load-Displacement Hysteretic Curves. The hysteretic curves of horizontal load displacement of two T-shaped wallboards are shown in Figures 20 and 21, and the following can be obtained by analyzing the hysteretic curves of the specimens [15]:

(1) The hysteretic curve of each wall clearly showed that the magnitudes of the positive and negative loads were asymmetric. The load value during the negative loading is much larger than that during the positive loading. In the process of applying horizontal load, the tension zones of the specimen for positive and negative forces are not the same, resulting in the difference in horizontal loads.

(2) The shapes and trends of hysteretic curves for the specimens are similar [16]. The slope value of the hysteretic curve loaded in the negative direction is higher than that of the hysteretic curve loaded in the positive direction; therefore the hysteretic curves were discussed and analyzed separately in the positive and negative directions [17].

(3) At the stage from negative loading to preyield, the hysteretic ring was long and narrow and did not contain large area. The shape of the peak of each hysteretic ring was shape. The peak values of the two curves under the same level of loading were basically the same and the curves basically coincided with each other. The slope was large and the slope decreased slowly, and it could be regarded as a straight line. The above curve characteristics proved that the wall was in the elastic range before yielding, but the impact of plasticity was small.

(4) During the stage from yield to peak, the slope of the curve decreased slightly, but not significantly, in the visual range; the value of the second load to the same displacement was smaller than the value of the first load; the shape of the opening at the peak of the hysteretic ring was larger than that before the yield and the area covered by the hysteretic ring was increased, but the increase was not obvious. The above phenomena indicated that the specimens were partially affected by plasticity at that moment.

(5) After the peak was entered, the slope of the curve toward the horizontal axis gradually increased, and the stiffness of the test piece decreased rapidly, while

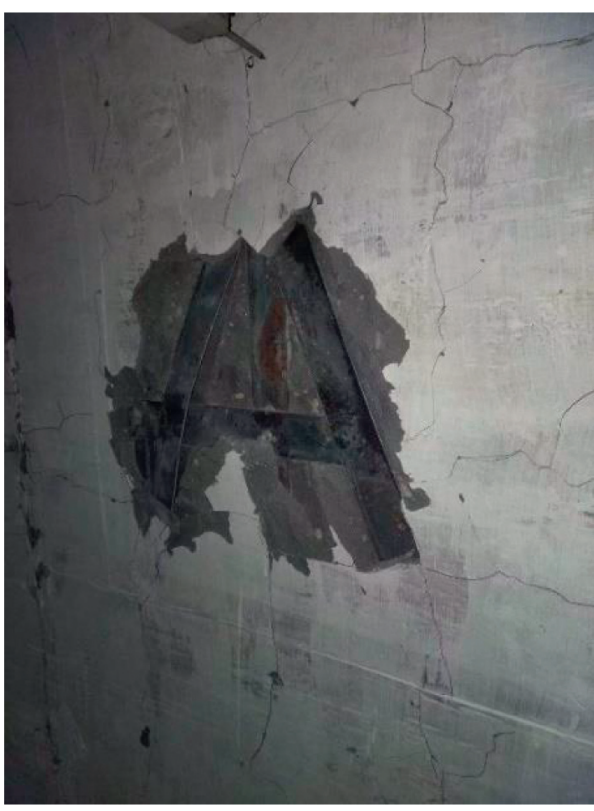

Figure 16: Buckling of oblique section steel.

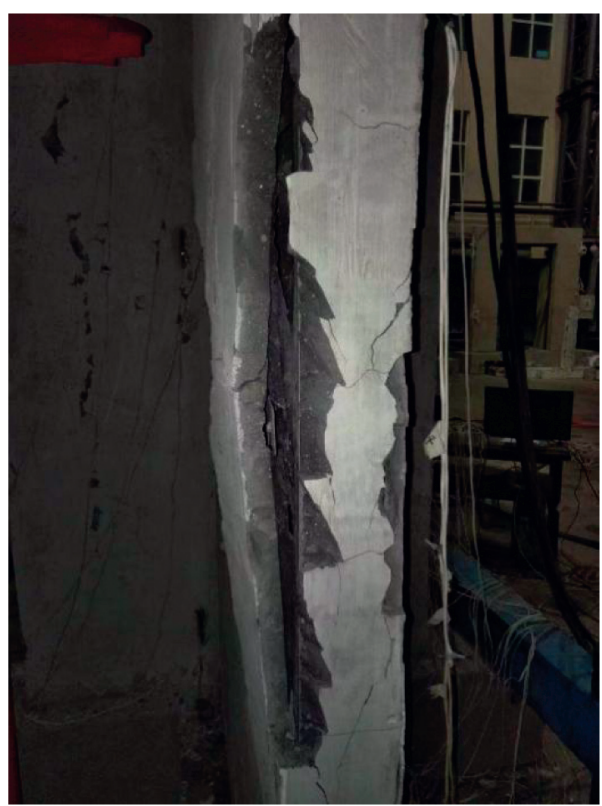

Figure 17: Lateral web cracks.

the opening at the peak position increased significantly. At the same time, the area of hysteretic ring also increased, and the energy consumption of the specimens also increased. During the process of loading at the same level, the maximum load value of the second cycle decreased more than that of the first cycle, which indicated that the specimen had completely entered the plastic stage after entering the peak.

In general, the shear capacity [16] of wall T-1 was slightly greater than that of wall T-2. The stiffness of the two 


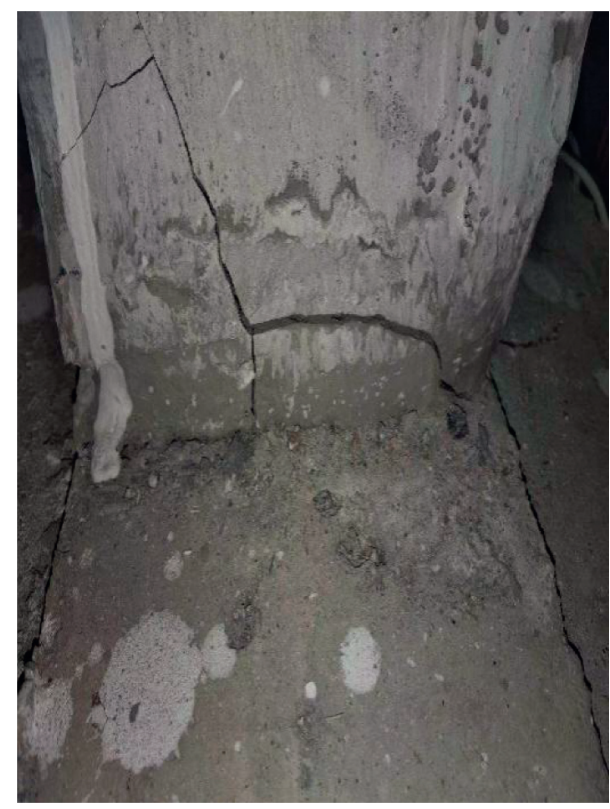

Figure 18: Cracks at the bottom of web.

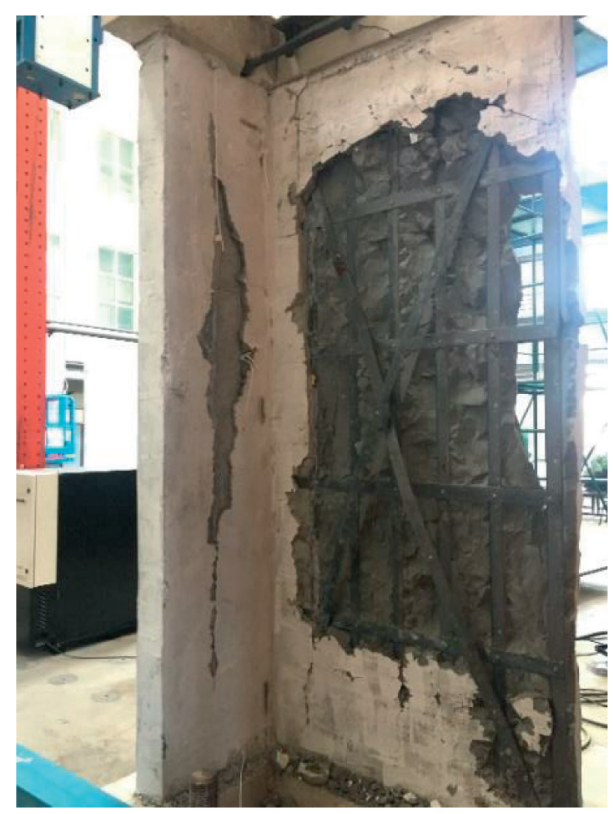

FIGURE 19: Final failure patterns.

specimens degraded fast after reaching the peak value in the process of negative loading process, but the stiffness degraded slowly in the process of positive loading. As the horizontal displacement of the specimen consistently increased, the area covered by the hysteretic ring also increased, but the overall figure was still not full enough.

3.3. Skeleton Curve Analysis. In this test, the comparison figure of the skeleton curve [18] of the relationship between horizontal load and vertex displacement of the two T-shaped wallboards was as follows.

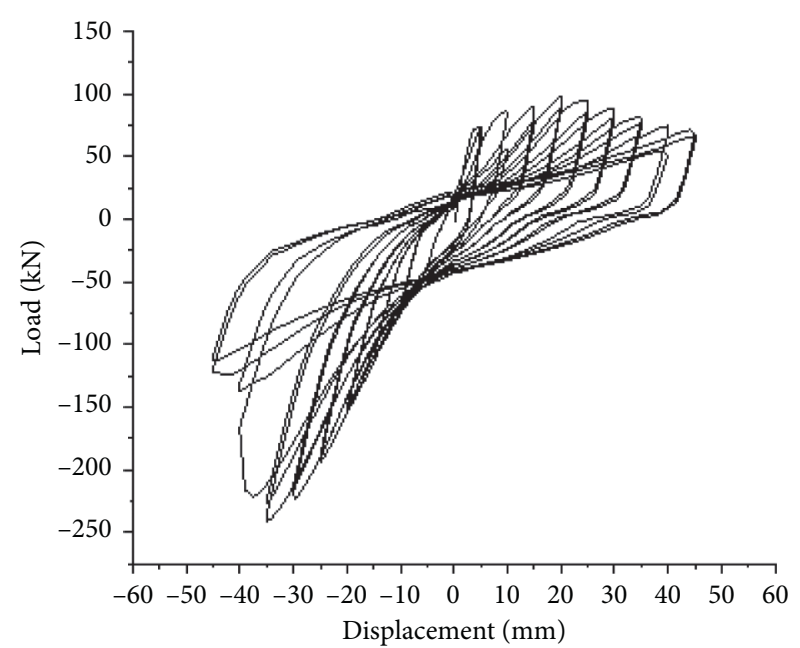

Figure 20: Hysteretic curve of specimen T-1.

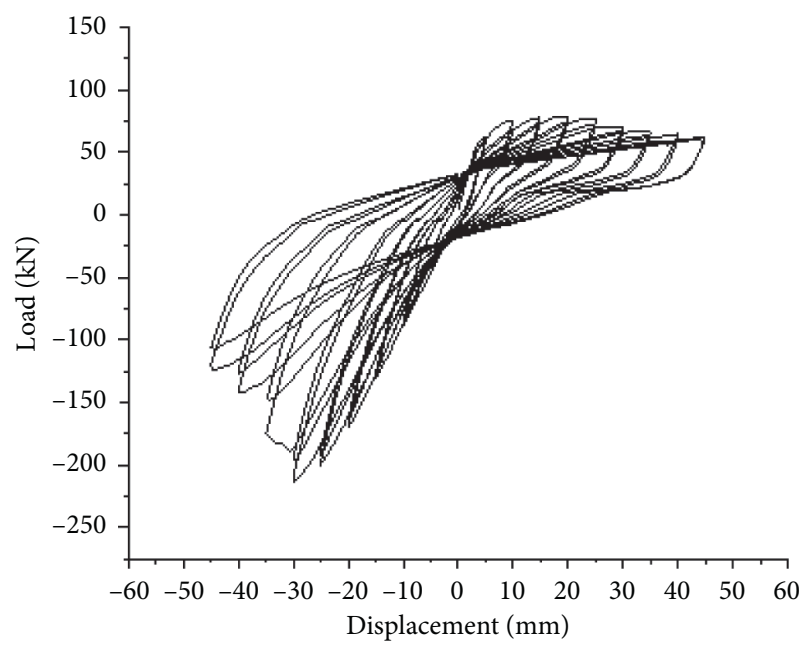

Figure 21: Hysteretic curve of specimen T-2.

The following can be seen from Figure 22:

(1) Before wall T-1 and wall T-2 reached the yield point, the skeleton curves were similar, and the shape of the curve was like a straight line. At that moment, the walls were in an elastic state. After the wall entered the yield stage, the skeleton curve bent, and the slope gradually decreased. A certain degree of plastic deformation was produced in the wall, and it entered a nonlinear state. When the positive loading was applied to the second cycle, the skeleton curve tended to bend and the positive yield load of the specimen was relatively small. Therefore, the specimen entered the yield stage.

(2) After the negative load of the two wall specimens reached the peak, the load suddenly dropped without obvious signs before. Moreover, the decline was rapid and the absolute value of the slope was large. Therefore, the shape of the skeleton curve was sharp at the peak. It indicated that the cumulative damage of the foamed concrete inside the wall was serious 
and the stiffness was rapidly degraded during the test. The foamed concrete is a brittle material, and this phenomenon indirectly proved the nature of foamed concrete.

(3) The number of sections in the wall was different. The space between steels inside wall T-1 was $150 \mathrm{~mm}$ and that inside wall T-2 was $200 \mathrm{~mm}$. Therefore, the steel contents in the walls were different, which made the bearing capacity of wall T-1 larger.

The load eigenvalues of the two walls in the test were calculated and summarized, as shown in Table 4.

3.4. Characteristic Analysis of Stiffness Degradation Curve. Before surface cracks appeared, cracks have appeared in the interior earlier and the stiffness has been degraded. In order to intuitively reflect the degree of stiffness degradation at each stage of the component cycle, formula (1) is used to express the secant stiffness at each stage of loading:

$$
K_{j}=\frac{\left(\sum_{i=1}^{n}\left|V_{j}^{i}\right|\right)}{\left(\sum_{i=1}^{n}\left|\Delta_{j}^{i}\right|\right)},
$$

where $K_{j}$ denotes stiffness under $j$ th load, $V_{j}^{i}$ denotes load value corresponding to the $i$ th cycle under the $j$ th load, and $\Delta_{j}^{i}$ denotes displacement value corresponding to the $i$ th cycle under the $j$ th load.

The stiffness-displacement curve of the specimen of the assembled light steel foamed concrete T-shaped wallboard is shown in Figure 23.

It can be seen from Figure 23 that the trends of stiffness changes of wall T-1 and wall T-2 were basically the same. The stiffness degradations of positive and negative displacements were asymmetric. In the case of positive loading, the initial slope was large, and the curve became gentle with the increase of load. It indicated that the stiffness degradation rate of the specimen was buffered compared with that at the initial time; in the first and middle stages of negative loading, the curve was relatively gentle, and the stiffness degradation was weak; in the later stage, the slope increased, and the stiffness degradation became more serious. The cumulative damage inside the specimen was large, the stiffness degradation was complete, and the plastic deformation was fully developed.

3.5. Ductility Analysis. Structural members with good ductility can absorb and consume more energy during the earthquake [19], which is beneficial to the seismic resistance of the structure. The ductility coefficient is usually used as the standard to evaluate the ductility of a structure. The formula is given as follows:

$$
\mu_{\Delta}=\left(\frac{\Delta_{u}}{\Delta_{y}}\right)
$$

where $\Delta_{u}$ is a limit displacement; $\Delta_{y}$ is a yield displacement.

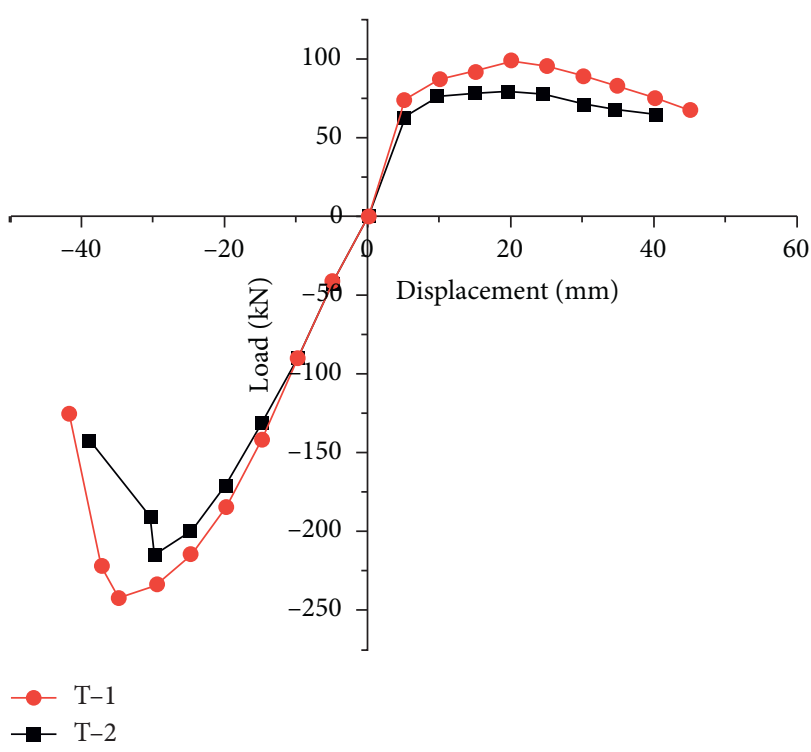

Figure 22: Specimen skeleton curve.

TABLE 4: Load eigenvalue table for specimens.

\begin{tabular}{lccccccc}
\hline \multirow{2}{*}{ Loading direction } & \multicolumn{3}{c}{ Yield point } & \multicolumn{2}{c}{ Peak value } & \multicolumn{2}{c}{ Ultimate } \\
point & \multicolumn{3}{c}{ point } \\
Specimen & Direction & $P_{y}$ & $\Delta_{y}$ & $P_{p k}$ & $\Delta_{p k}$ & $P_{u}$ & $\Delta_{u}$ \\
& & $(\mathrm{kN})$ & $(\mathrm{mm})$ & $(\mathrm{kN})$ & $(\mathrm{mm})$ & $(\mathrm{kN})$ & $(\mathrm{mm})$ \\
\hline \multirow{2}{*}{$\mathrm{T}-1$} & Positive & 82.7 & 8.4 & 98.3 & 20 & 83.6 & 34 \\
& Negative & 234.9 & 30.6 & 241.9 & 35 & 205.6 & 38.2 \\
\hline \multirow{2}{*}{$\mathrm{T}-2$} & Positive & 70.1 & 7.6 & 79.1 & 19.45 & 67.2 & 35.2 \\
& Negative & 205.6 & 26.9 & 214.5 & 30 & 182.3 & 32 \\
\hline
\end{tabular}

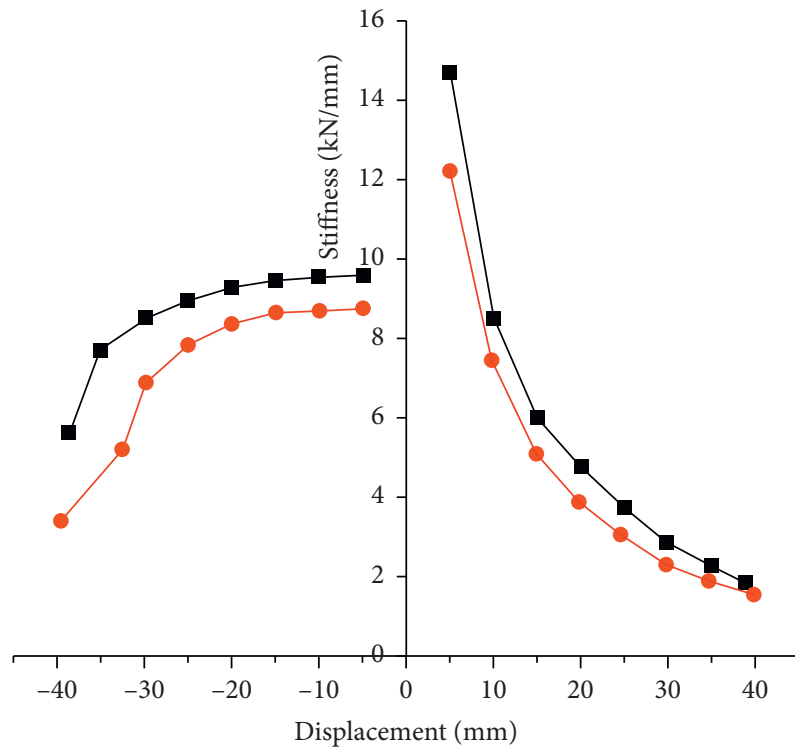

Speciment T-1

Speciment $\mathrm{T}-2$

FIGURE 23: Stiffness degradation curve of specimens. 
The displacement and ductility coefficients in this test are shown in Table 5.

The results and discussion may be presented separately, or in one combined section, and may optionally be divided into headed subsections.

It can be seen from Table 5 that the differences between the ductility values of the two specimens were small, that the ductility of specimen T-2 was slightly higher than that of specimen T-1, and that the ductility of positive loading was better than that of negative loading. In general, a structural member with a ductility greater than 3 is superior. However, the ductility of the two specimens in this test was less than 3 . Foamed concrete is a brittle material. The properties of this material have a certain effect on the ductility of the component. The ductility of the two specimens was relatively small, which indicated that, during the test process, the stiffness of the specimens degraded rapidly after they entered the yield stage, indicating that the ductility was insufficient.

3.6. Energy Consumption Capacity Analysis. Nowadays, the criteria used to determine whether the energy consumption of a structural member is good or not include the following: equivalent viscous damping coefficient $h_{e}$, energy dissipation coefficient $E$, work ratio index $I_{w}$, and the like. The equivalent viscous damping coefficient was proposed by Jacobson at the beginning of this century, and it was used as an indicator to determine the energy consumptions of structural members in postmodern seismic engineering projects. The equivalent viscous damping coefficient of the specimen could be expressed by the hysteretic ring area shown in Figure 24, and the formula was as follows:

$$
h_{e}=\frac{1}{2 \pi} \times\left(\frac{S_{\mathrm{ABCD}}}{S_{\triangle \mathrm{OBE}}+S_{\triangle \mathrm{ODF}}}\right) \text {. }
$$

In Figure 24, $S_{\mathrm{ABCD}}$ represents the energy consumption of structural members in a single load and $S_{\triangle \mathrm{OBE}}+S_{\triangle \mathrm{ODF}}$ represents the energy absorbed by elastic members under ideal conditions. The ratio of the two areas is the ratio of the energy consumed to the energy absorbed by the equivalent elastomer when it has the same deformation. The higher the ratio value $h_{e}$ is, the better the energy consumption of the structural members is. In this test, a single hysteretic ring with the ultimate load was selected, and the calculation results were shown in Table 6.

\section{Finite Element Model Analysis of Section Steel Foamed Concrete T-Shaped Wallboard}

\subsection{Establishment of the Finite Element Model}

4.1.1. Constitutive Relationship of Foamed Concrete. The concrete damage plasticity model has good convergence. At present, this model is usually used for calculation in the nonlinear analysis of concrete structures. In this paper, this model was also adopted for calculation in simulation analysis, with tensile failure and compression failure of concrete as the main failure mechanism. See Table 7 for specific parameters.
TABLE 5: The test of displacement and ductility coefficient.

\begin{tabular}{lccccccc}
\hline \multirow{2}{*}{ Specimen } & \multicolumn{3}{c}{ Positive } & \multicolumn{3}{c}{ Negative } & Average \\
& $\Delta_{u}$ & $\Delta_{y}$ & $\mu_{\Delta}$ & $\Delta_{u}$ & $\Delta_{y}$ & $\mu_{\Delta}$ & $\overline{\mu_{\Delta}}$ \\
\hline T-1 & 34 & 8.4 & 4.0 & 38.2 & 30.6 & 1.3 & 2.7 \\
T-2 & 35.2 & 7.6 & 4.6 & 32 & 26.9 & 1.2 & 2.9 \\
\hline
\end{tabular}

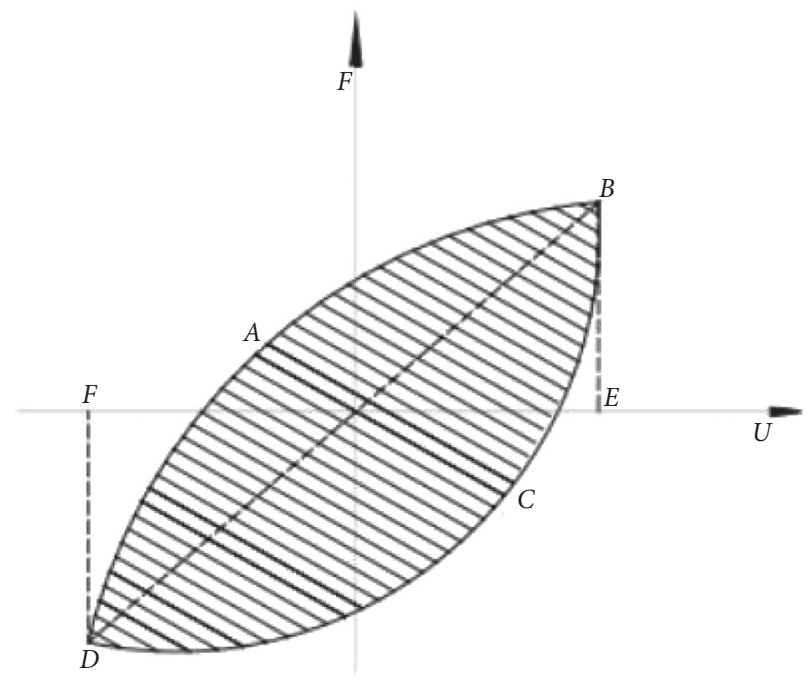

FIgURE 24: Equivalent viscous damping coefficient diagram.

TABLE 6: Energy consumption coefficient table.

\begin{tabular}{lcc}
\hline Specimen & $\mathrm{T}-1$ & $\mathrm{~T}-2$ \\
\hline Equivalent viscous damping coefficient $(h e)$ & 0.2 & 0.14 \\
\hline
\end{tabular}

TABLE 7: Plastic damage model parameters of concrete.

\begin{tabular}{lcccc}
\hline $\begin{array}{l}\text { Expansion } \\
\text { angle }\end{array}$ & Eccentricity & $\left(f_{b_{0}} / f_{c_{0}}\right)$ & $K$ & $\begin{array}{c}\text { Viscosity } \\
\text { coefficient }\end{array}$ \\
\hline 30 & 0.1 & 1.16 & 0.6667 & 0.0005 \\
\hline
\end{tabular}

The material in this paper was high-density foamed concrete. The constitutive relation expression of foamed concrete developed by He Shuming was selected as follows:

$$
y= \begin{cases}-1.041 x^{3}+1.019 x^{2}+1.028 x-0.017, & 0 \leq x \leq 1, \\ 204 x^{3}-674 x^{2}+737.1 x-266.1, & 1 \leq x \leq 1.2, \\ -0.005 x^{3}+0.052 x^{2}-0.211 x-0.574, & x>1.2\end{cases}
$$

where $x$ is the ratio of strain to peak strain and $y$ is the ratio of strain to yield strength.

The schematic diagram of the concrete constitutive relationship of foamed concrete is shown in Figure 25. 


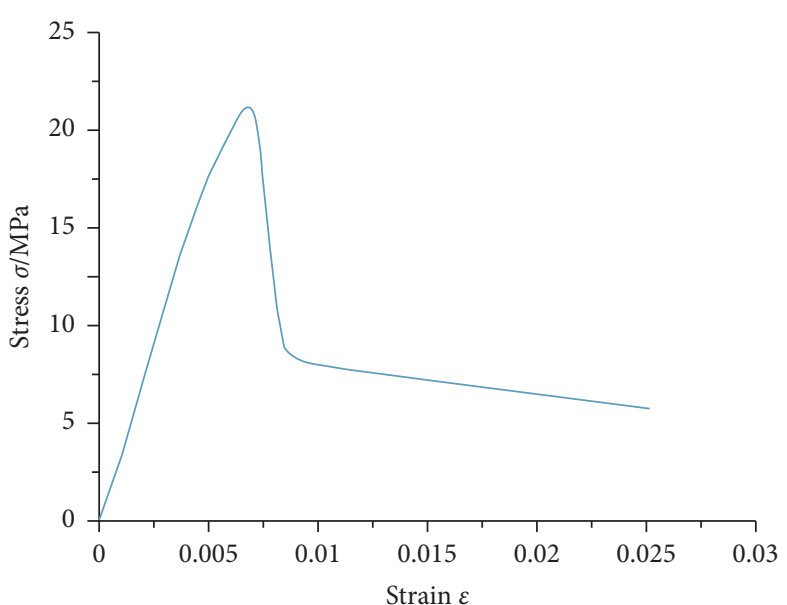

(a)

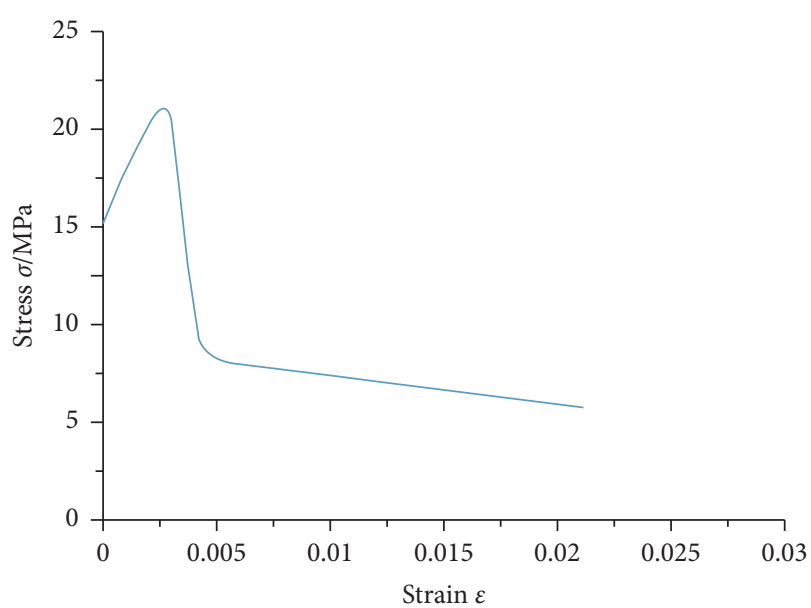

(b)

Figure 25: Constitutive equation of foam concrete. (a) Stress-strain curve. (b) Plastic stress-strain curve.

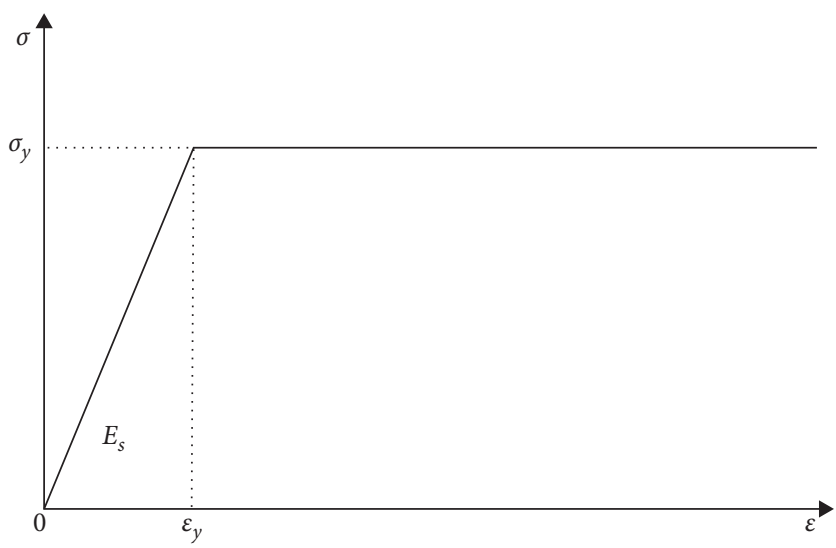

Figure 26: Constitutive curve of steel.

4.1.2. Constitutive Relation of Steel. In order to simplify the calculation, the complete elastoplastic model was adopted in the simulation; that is, the strengthening stage was not considered after yield, so the stress-strain relationship was expressed as a straight line, as shown in Figure 26.

In the figure, $\sigma$ is stress of steel, $\varepsilon$ is strain of steel, $\varepsilon_{y}$ is strain corresponding to yield strength, $f_{y}$ is yield strength of steel, and $E_{s}$ is elastic modulus of steel.

4.1.3. Yield Criterion. In this paper, von Mises yield criterion is selected, and its expression is

$$
\left(\sigma_{e}-\sigma_{y}\right)=0
$$

where $\sigma_{e}$ is equivalent stress and $\sigma_{y}$ is yield stress.

The following is the calculation formula of equivalent stress $\sigma_{e}$ :

$$
\sigma_{e}=\sqrt{\left.\frac{1}{2}\left[\left(\sigma_{1}-\sigma_{2}\right)^{2}+\left(\sigma_{1}-\sigma_{3}\right)\right]^{2}+\left(\sigma_{3}-\sigma_{1}\right)\right]^{2}},
$$

or

$$
\sigma_{e}=\sqrt{\frac{1}{2}\left[\left(\sigma_{x}-\sigma_{y}\right)^{2}+\left(\sigma_{y}-\sigma_{z}\right)^{2}+\left(\sigma_{z}-\sigma_{x}\right)^{2}+6\left(\tau_{x y}^{2}+\tau_{y z}^{2}+\tau_{z x}^{2}\right)\right]}
$$

where $\sigma_{1}, \sigma_{2}, \sigma_{3}$ denote principal stress and $\sigma_{e}, \sigma_{e}, \sigma_{e}, \tau_{x y}^{2}, \tau_{x y}^{2}, \tau_{x y}^{2}$ denote stress components.

4.1.4. Establishment of Geometric Models. According to the actual situation, two specimens $\mathrm{T}-1$ and $\mathrm{T}-2$ with different spaces between steels were, respectively, modeled and analyzed in this paper, with a modeling ratio of $1: 1$.

Three-dimensional solid element, C3D8R, was selected for foamed concrete, and the eight-node linear reduction integral algorithm was applied; the thickness of steel was only $2 \mathrm{~mm}$, far less than the lengths in the other two directions. Therefore, the shell element (S4R) was adopted to simulate cold-formed thin-walled light steel. In the modeling process, in order to enable the mesh to be divided in a neat way, the entire steel skeleton was merged with the Merge function to form a whole to ensure its stability. The specific geometric model is shown in Figure 27. 


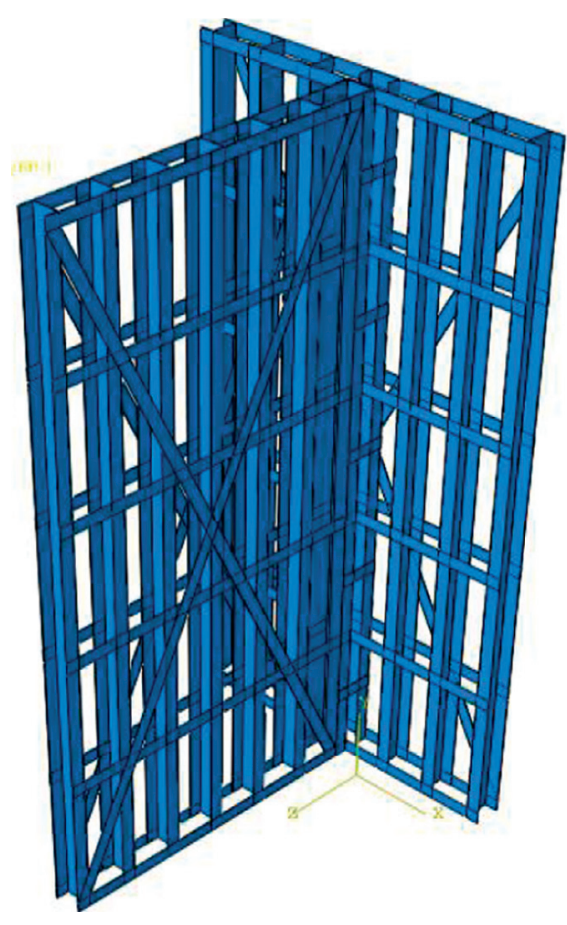

(a)

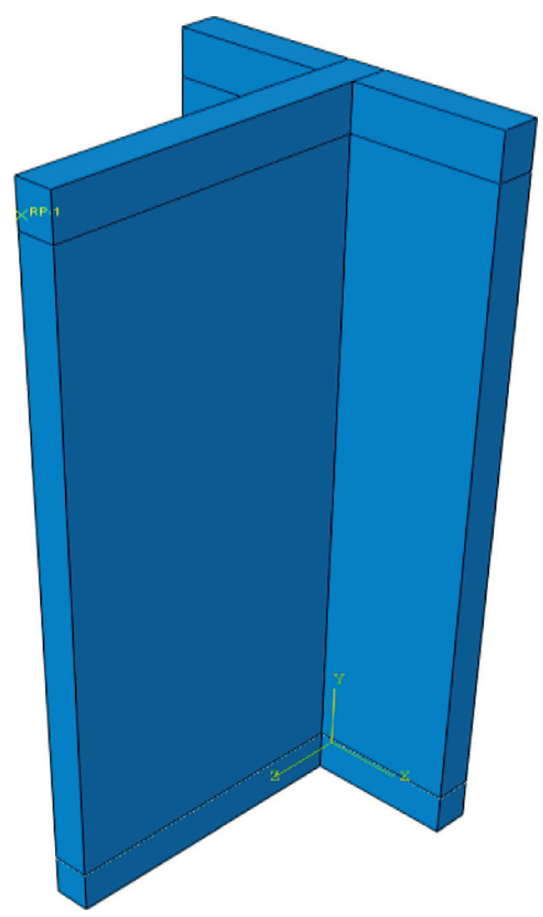

(b)

FIgURE 27: Finite element model of wall. (a) T-2 steel skeleton model. (b) Overall geometric model.

The embedded element function was used to embed the whole steel skeleton into the foamed concrete wallboard to simulate the bond relationship between foamed concrete and steel in practice. In the simulation, the complete elastomer was adopted in the loading beam and the bottom beam; namely, the elastomer only had the elastic modulus and density but its plasticity was not defined. At the same time, the reinforcement in the beam was not set, and the contact surface between both beams and the wall was set as a tie constraint.

The boundary conditions of the bottom beam were set, and fixed constraints were provided to horizontal and rotational degrees of freedom of the lower surface of the bottom beam. Two analysis steps, Step-1 and Step-2, were established. Among them, Step-1 was the vertical load acting on the centroid of the wall; a load point RP-2 was created at a place which was $50 \mathrm{~mm}$ away from the lateral center of the load beam, and coupling constraint connection was performed between the load point and the lateral surface of the loading beam.

When the meshes were divided, a comprehensive balance was made as follows: and the meshes on the main parts were divided densely, while those on the secondary parts were divided sparsely, as shown in Figure 28.

4.2. Finite Element Results Analysis. Submit the operation in the job module and extract the simulation results after calculation. The following are the Mises stress nephograms of the steel and foamed concrete inside specimens T- 1 and T-2 under different displacement values.
Figure 29 shows the stress nephogram of the specimen T-1 steel skeleton under positive loading of $20 \mathrm{~mm}$ and negative loading of $20 \mathrm{~mm}$, which can be seen from the figure: the force exerted on the specimen T-1 steel was mainly generated at the bottom of the wall and gradually decreased along the direction of wall height, and the upper section of the steel was subject to the weakest force.

The force that acted on the flange plate was basically horizontal, because the force was along the direction of the web. The flange was mainly subject to bending moment. Due to the asymmetry of section, the load under negative loading was higher than that under positive loading. Both the lateral drawn flat steel and the diagonal drawn flat steel were subject to a certain force to ensure the overall stability.

Different from the flange plate, the web was mainly subjected to shear force. During positive loading, the red area was mainly in the middle and lower sections of the steel far from the flange plate and therefore the stress there was greater. During negative loading, however, the middle and lower sections of the steel near the flange plate were subject to a greater force.

It can be seen that, no matter in the positive or negative loading, the middle lower part of the oblique drawn flat steel near the flange plate in the web was always subject to a great force. At the same time, the lateral drawn flat steel in the middle was also subject to a great force. In the test on specimen T-1, the oblique drawn flat steel here first buckled. This phenomenon in the simulation was similar to that in the actual situation and they were consistent with each other.

Figure 30, corresponding to Figure 29, shows the stress nephogram of the foamed concrete T-shaped wall under the 


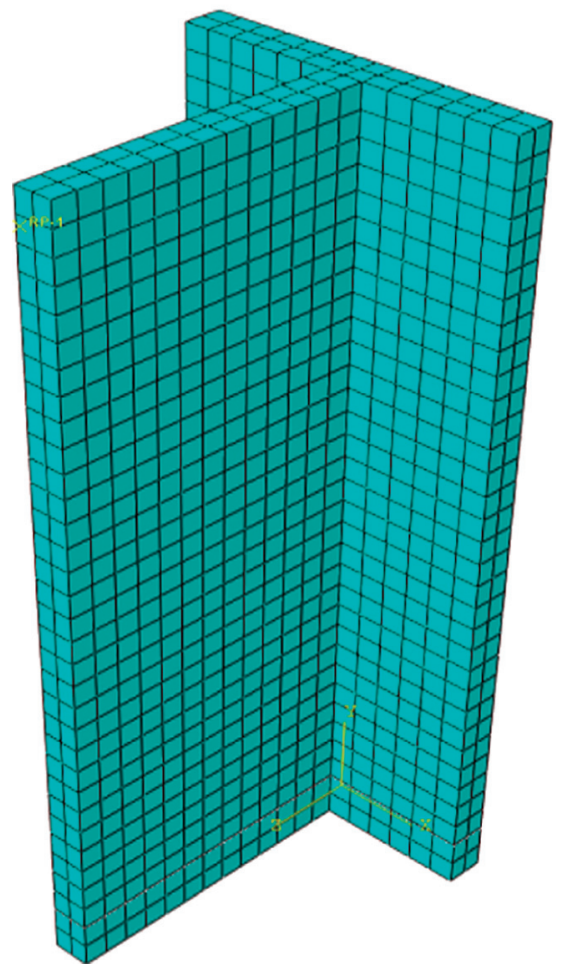

(a)

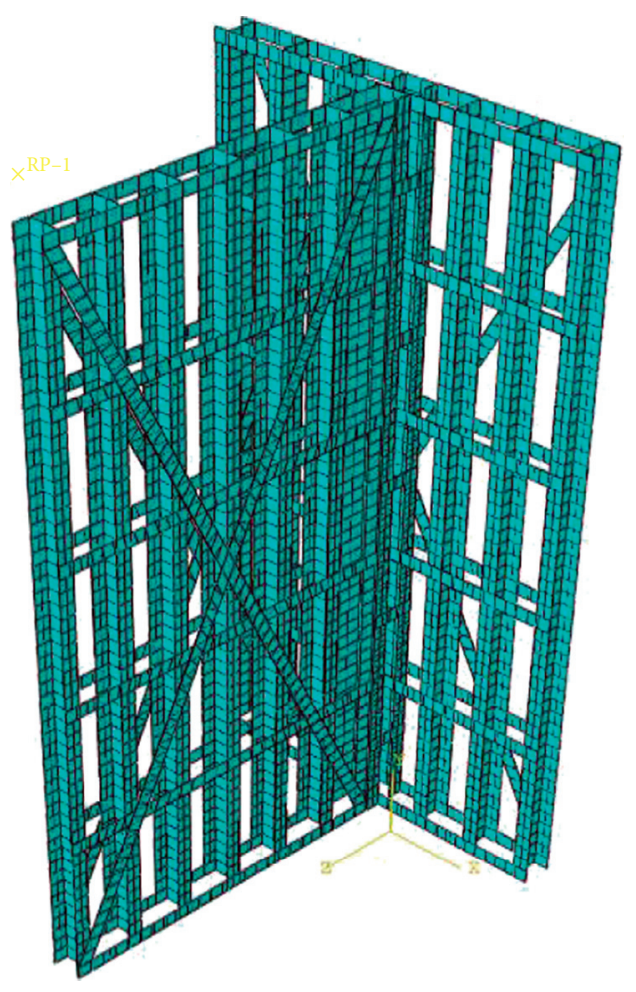

(b)

FigurE 28: Specimen mesh generation. (a) Mesh division for foamed concrete. (b) Mesh division for steel skeleton.

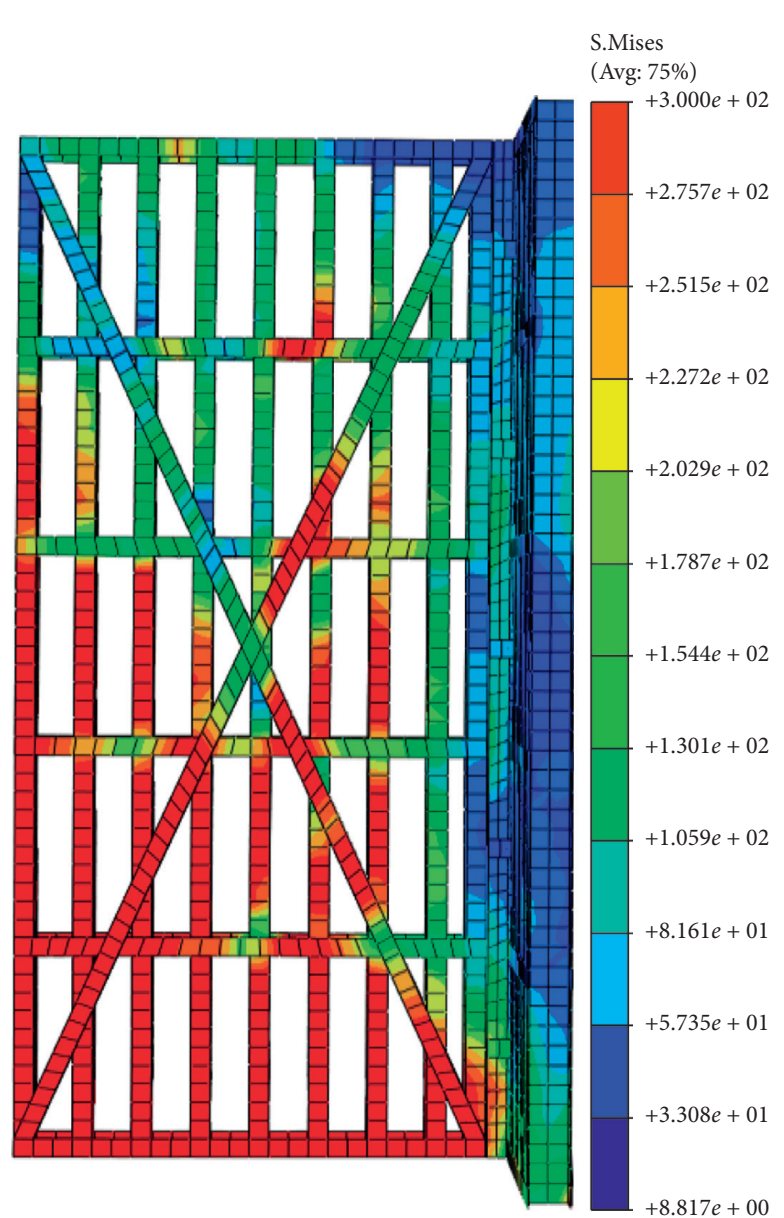

(a)

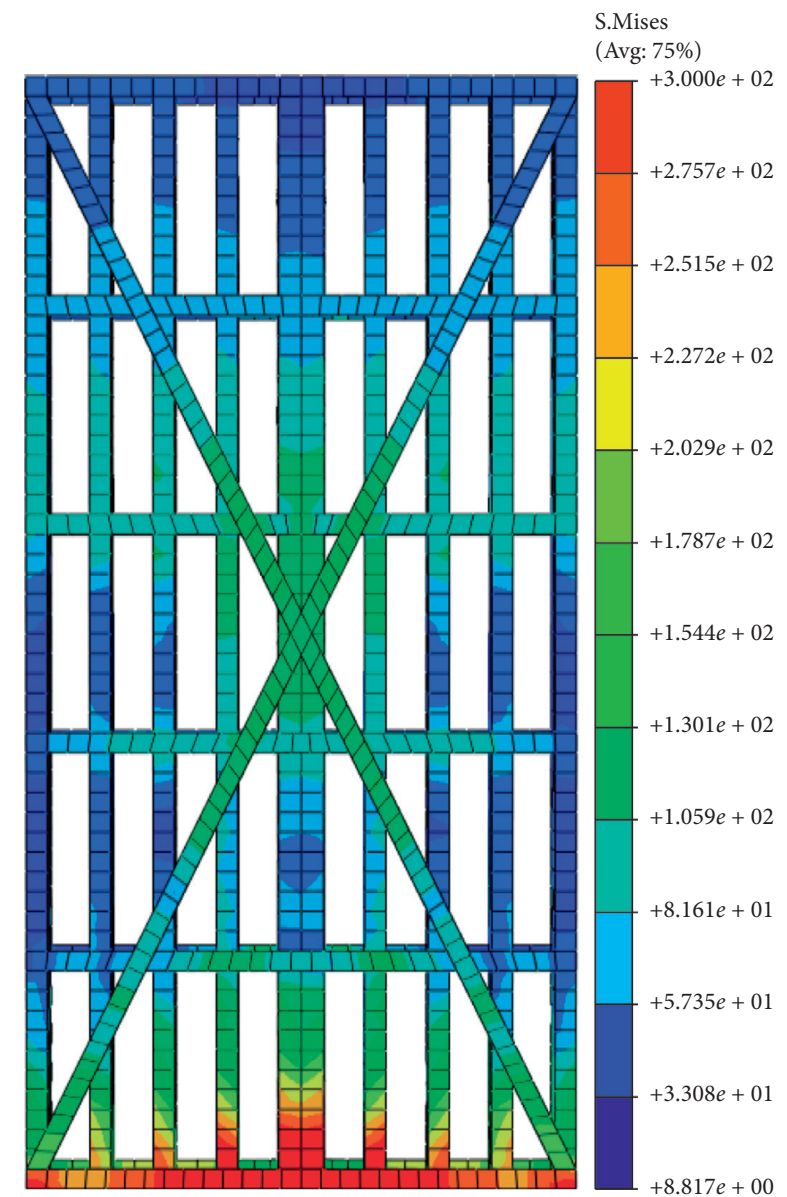

(b)

Figure 29: Continued. 


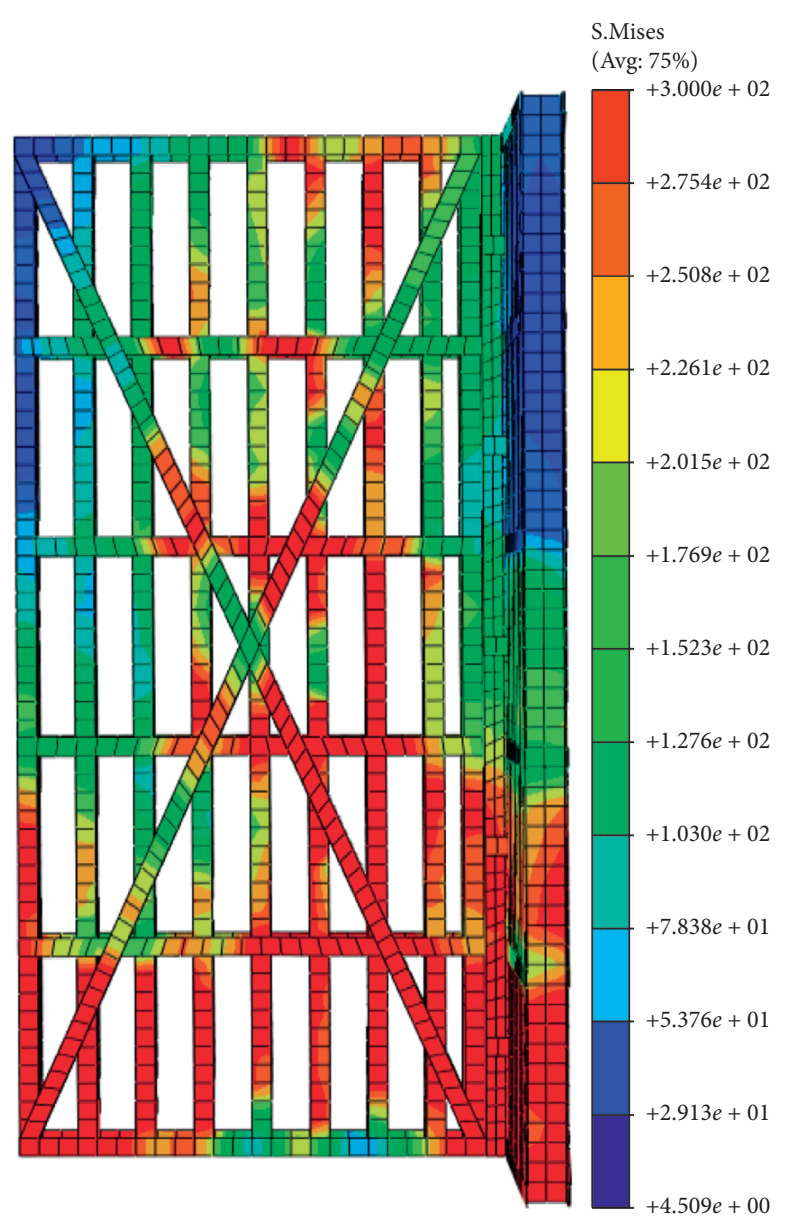

(c)

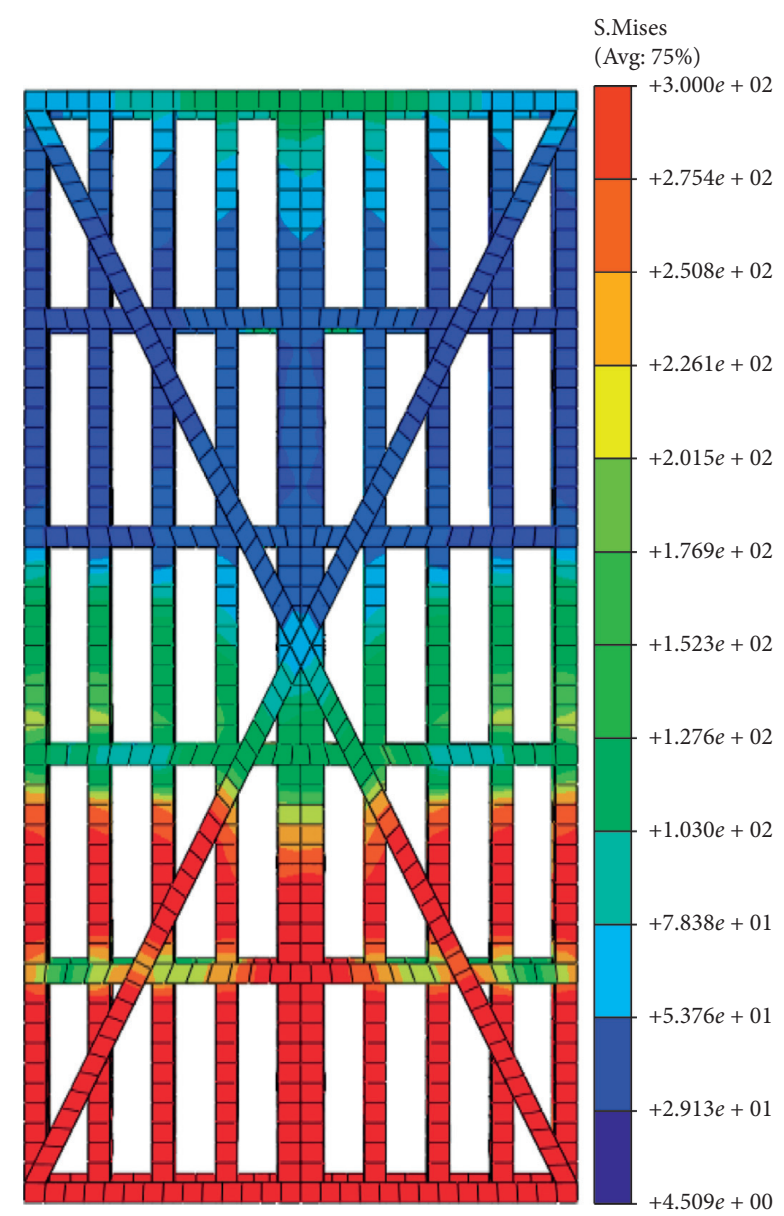

(d)

Figure 29: Stress nephogram of T-1 steel skeleton. (a) Positive loading of web. (b) Positive loading of flange. (c) Negative loading of web. (d) Negative loading of flange.

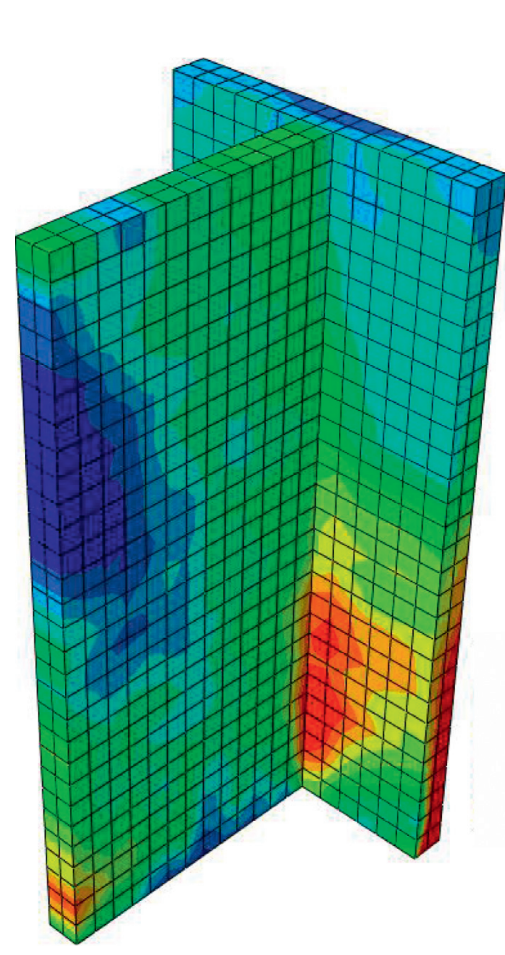

(a)
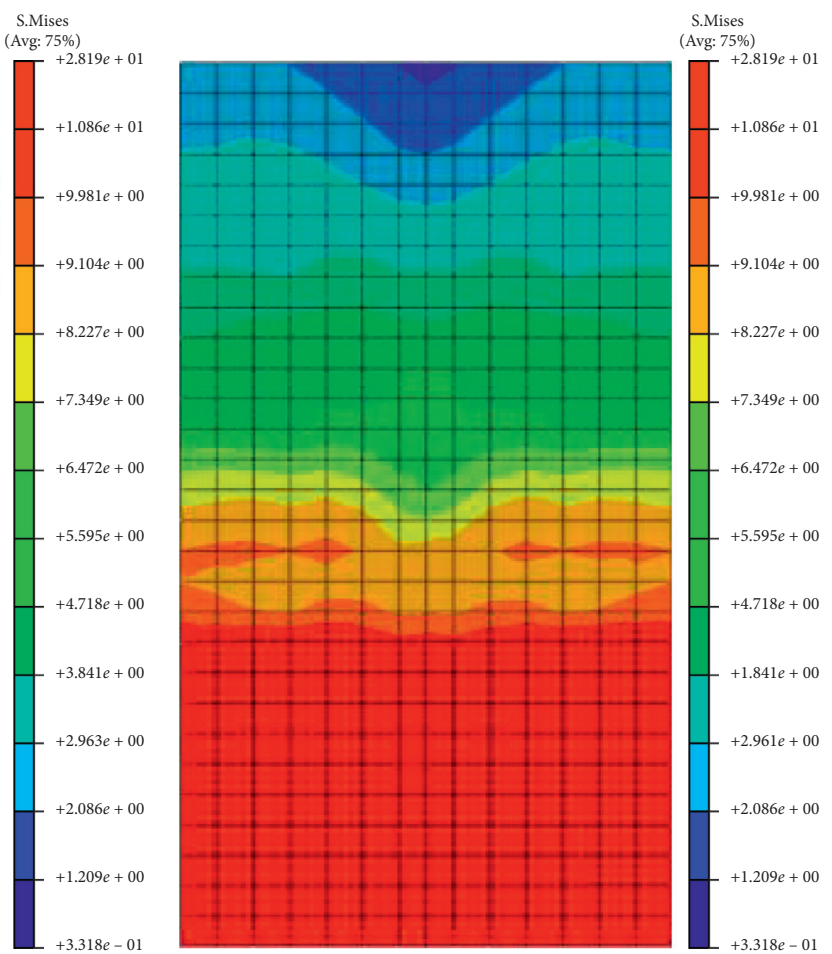

(b)

FIgURe 30: Continued. 


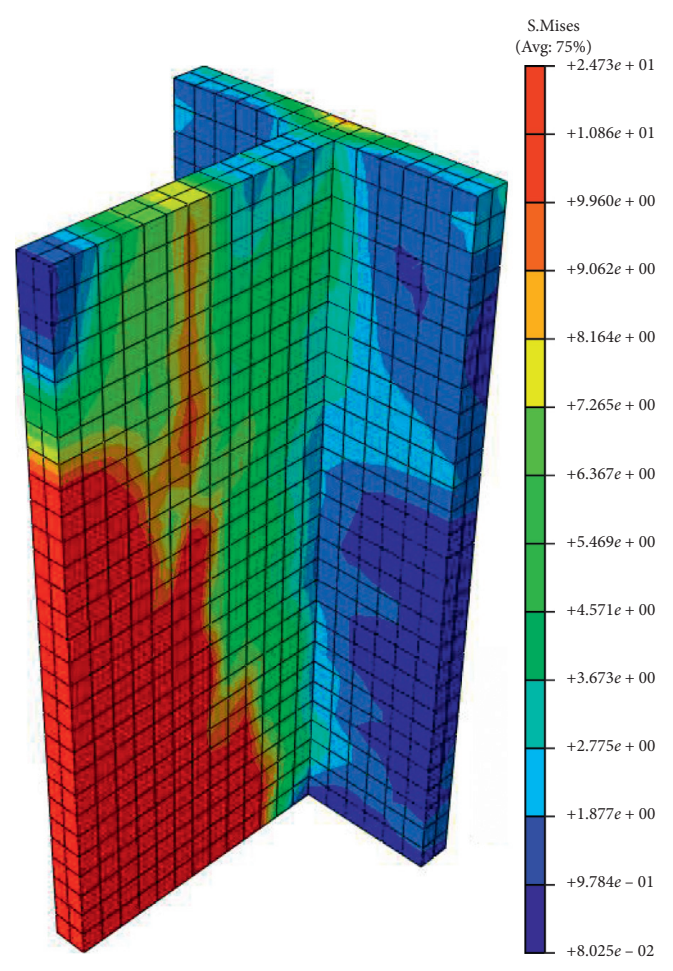

(c)

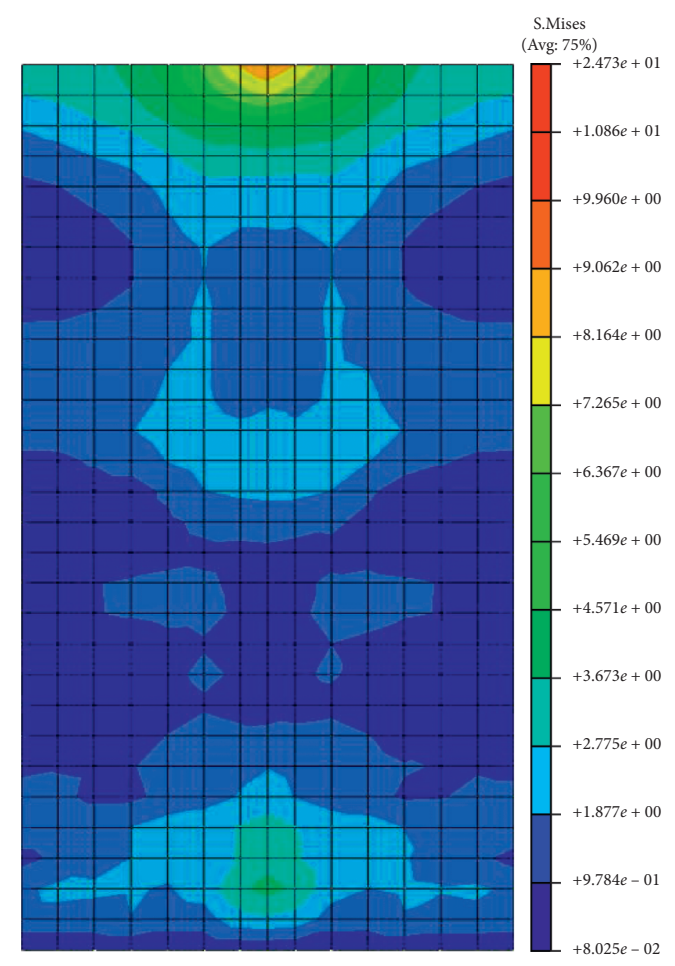

(d)

Figure 30: Stress nephogram of specimen T-1 wall. (a) Positive loading of web. (b) Positive loading of flange. (c) Negative loading of web. (d) Negative loading of flange.

positive and negative loading of $20 \mathrm{~mm}$, respectively. In the case of positive loading, the web was less stressed, the flange plate was pulled on the front side, and the reverse side was pressed; the pressed area was red, and the force was great; in the case of negative loading, the stress on the flange plate was relatively weak, while the stress on the web was relatively strong; at this moment, the red area of the web was in the middle and lower parts away from the flange plate, which belonged to the pressed area.

The stress distributions of specimen T-2 and specimen $\mathrm{T}-1$ under the same displacement were approximately the same. In both cases, the stress at the bottom was the maximum, and the force decreased gradually along the wall height. The outermost section of the web was subject to the greatest force. The failure phenomenon of wall foamed concrete and that of specimen $\mathrm{T}-1$ were roughly the same.

\subsection{Comparative Analysis of Finite Element Simulation and} Experimental Data. After the calculation was completed, the simulated data was exported and summarized and sorted. In this section, the hysteretic curves and skeleton curves [16] of specimens T-1 and T-2 were selected to analyze the eigenvalues of the loads and compare them in the test. The results were shown in Figure 31.

Figure 28 shows the comparison of hysteretic curves of wall T-1 and wall T-2. The simulated and experimental hysteretic curves were roughly of the same shape, but there were still some differences. The area of a single hysteretic ring in simulation was larger than that of single hysteretic ring in the test. As a whole, the simulation curve slightly wrapped up the experimental curve, and the simulated hysteretic curve had some gathering effects. Comparison of the skeleton curves was shown in Figure 32.

It can be seen from the comparison of the skeleton curves [18] that the experimental values were close to the simulated values, that the simulated peak load was larger than the experimental peak load, and that the slopes of the curves when the two specimens were simulated under negative load were greater than the slopes in the tests. At the beginning, they were in the elastic phase, the curves approximately appeared as straight lined, and then they entered the yield stage, and the curves bent. During negative loading, the curve showed relatively complete ups and downs. During positive loading, however, the ascending segment was more obvious, while the trend of the downward segment of the curve was more obscure after reaching the peak, and the curve in the later period was relatively gentle, which can be understood that foamed concrete was no longer working and steel became the main forced member. Comparison of the eigenvalues of wall test and simulated load is given in Table 8 .

It can be seen from Table 8 that there were some errors between the finite element simulation values and the 


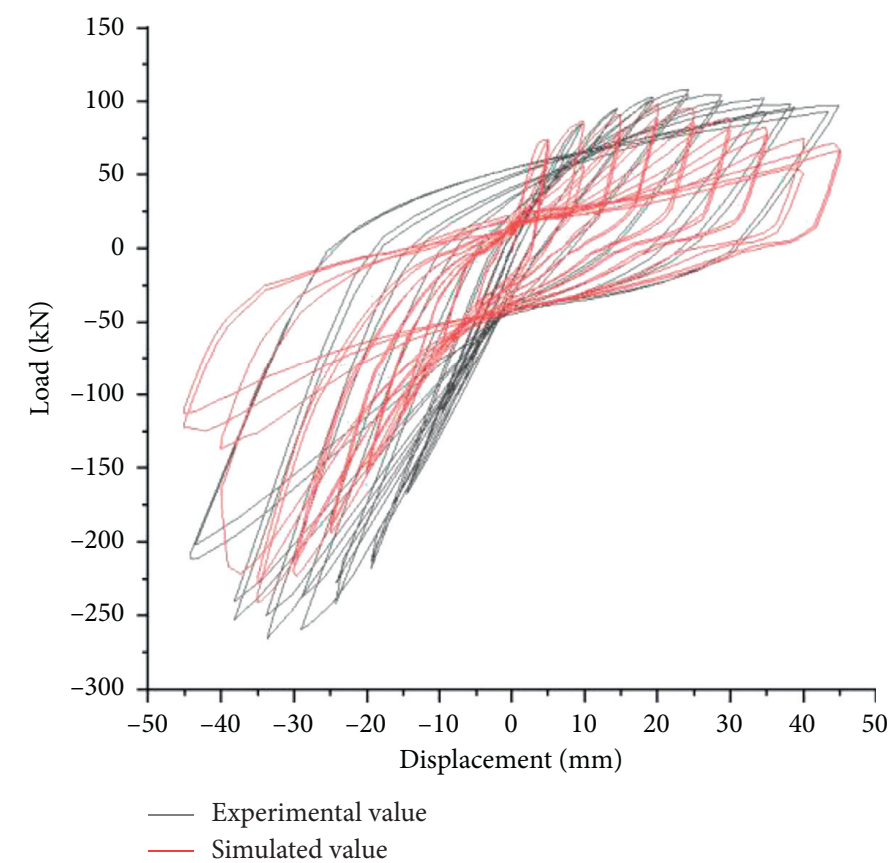

(a)

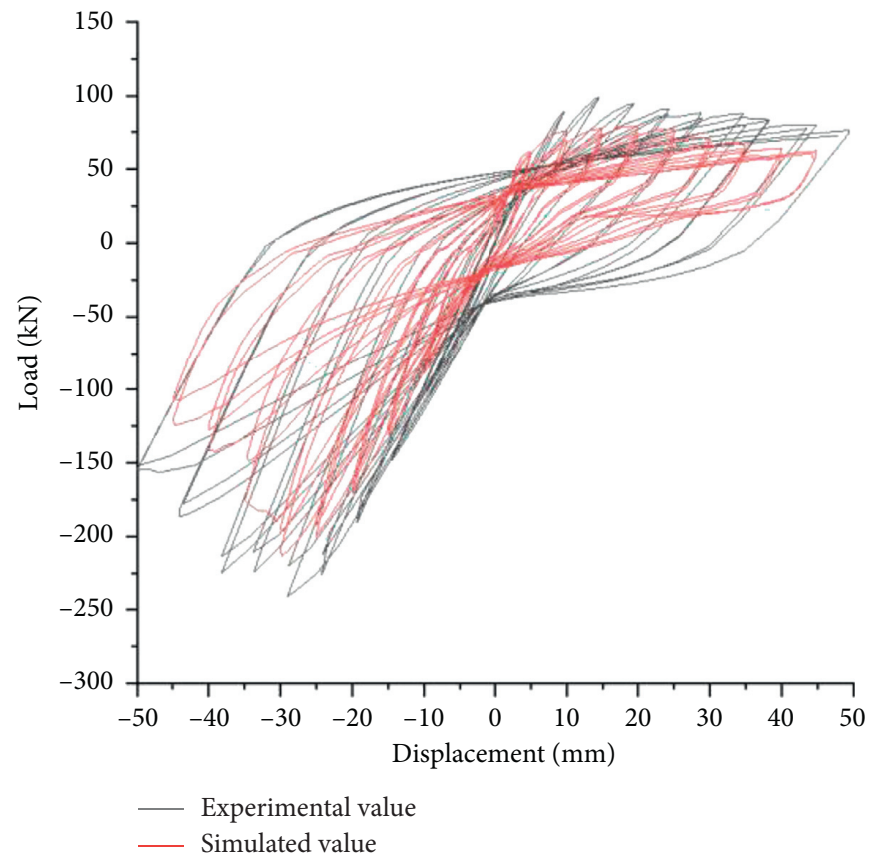

(b)

FiguRE 31: Comparison of experimental and simulated hysteretic curves. (a) Hysteretic curve of specimen T-1. (b) Hysteretic curve of specimen T-2.

experimental values in the low-cycle reciprocating loading. But both curves were roughly the same. It is found by dividing the experimental value with the simulated value that the error of wall T-1 was smaller than that of wall T-2. The maximum difference between the experimental and simulated values of wall T-1 was $9 \%$, while that of wall T-2 was $21 \%$. It can be determined that the experimental value and the simulated value were within the range of permissible errors. From the overall perspective of the simulation analysis, the bearing capacity of wall T-1 was higher than that of wall $\mathrm{T}-2$, which was consistent 


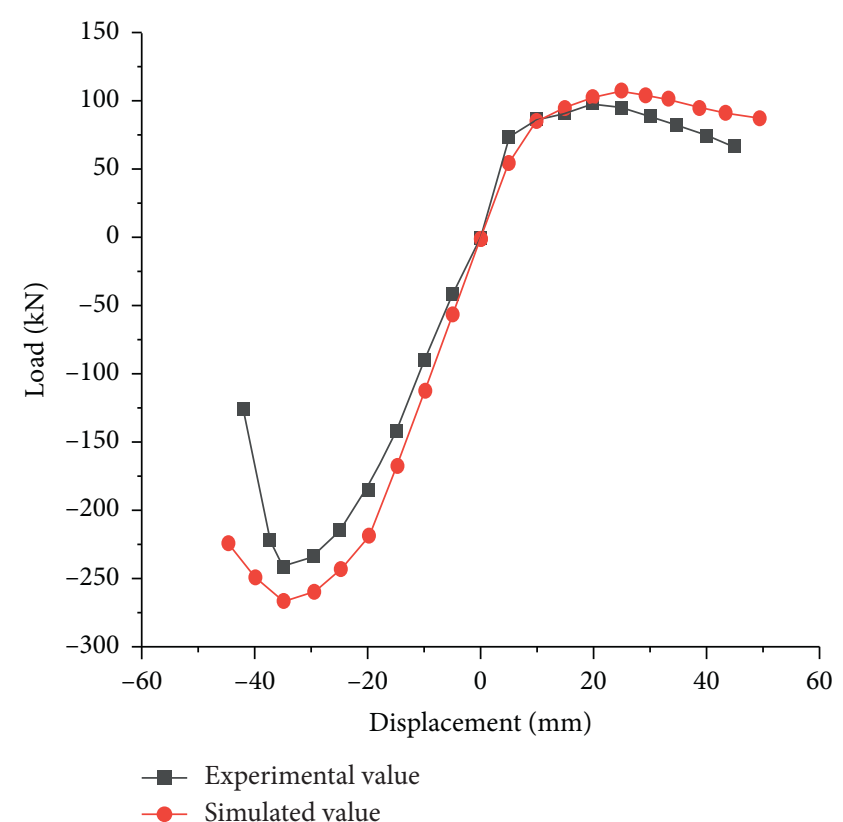

(a)

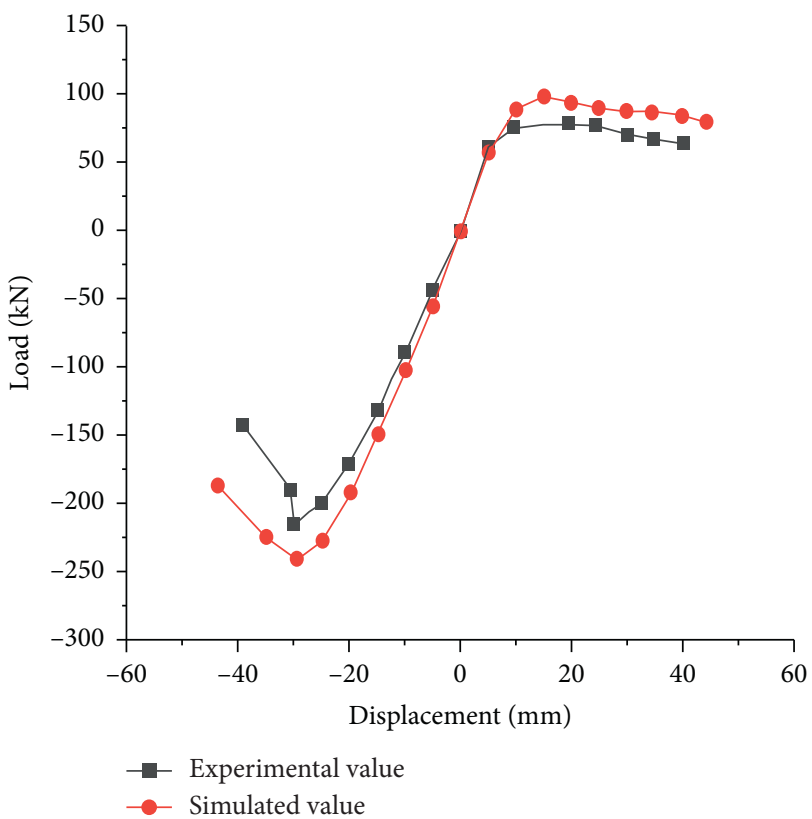

(b)

FIgURE 32: Comparison of experimental and simulated skeleton curves. (a) Skeleton curve of specimen T-1. (b) Skeleton curve of specimen T-2.

TABLE 8: Comparison of the eigenvalues of wall test and simulated load.

\begin{tabular}{|c|c|c|c|c|c|c|c|}
\hline \multirow[b]{2}{*}{ Eigenvalue } & \multirow[b]{2}{*}{$\begin{array}{l}\text { Loading } \\
\text { direction }\end{array}$} & \multicolumn{3}{|c|}{ Specimen T-1 } & \multicolumn{3}{|c|}{ Specimen T-2 } \\
\hline & & $\begin{array}{l}\text { Experimental } \\
\text { value }\end{array}$ & $\begin{array}{l}\text { Simulated } \\
\text { value }\end{array}$ & $\begin{array}{c}\text { Difference } \\
\text { value }\end{array}$ & $\begin{array}{l}\text { Experimental } \\
\text { value }\end{array}$ & $\begin{array}{l}\text { Simulated } \\
\text { value }\end{array}$ & $\begin{array}{c}\text { Difference value } \\
(\%)\end{array}$ \\
\hline \multirow{2}{*}{ Yield load $(\mathrm{kN})$} & Positive & 82.7 & 90.3 & 8 & 70.1 & 88.5 & 21 \\
\hline & Negative & -234.9 & -249.5 & 6 & -205.6 & -222.9 & 8 \\
\hline \multirow{2}{*}{ Peak load $(\mathrm{kN})$} & Positive & 98.3 & 107.7 & 9 & 79.1 & 98.8 & 20 \\
\hline & Negative & -241.9 & -266.3 & 9 & -214.5 & -240.8 & 11 \\
\hline \multirow{2}{*}{$\begin{array}{l}\text { Ultimate load } \\
(\mathrm{kN})\end{array}$} & Positive & 83.6 & 91.6 & 9 & 67.2 & 83.9 & 20 \\
\hline & Negative & -205.6 & -226.4 & 9 & -182.3 & -204.7 & 11 \\
\hline
\end{tabular}

with the experimental results. The following conclusion can be made: the denser the internal steel is, the higher the bearing capacity will be [20].

\section{Conclusions}

In this paper, a new idea (method) of joint connection is proposed. Two walls were made and tested to observe the failure phenomenon of T-shaped wall under the action of low-cycle reciprocating loading, analyze the failure mechanism, and study the shear bearing capacity, deformation performance, ductility, and energy consumption capacity of the test wall. ABAQUS software was selected to carry out finite element simulation and compare the simulated the experimental results, and the main conclusions were as follows:

(1) Under the action of low-cycle reciprocating loading, the flange plate of $\mathrm{T}$-shaped wall was mainly subjected to the action of bending moment and had slight transverse horizontal cracks. The main damage occurred at the web. There were many vertical cracks on the right and bottom of the web, with the vertical cracks corresponding to the positions of the steels. At the later stage, the buckling of oblique drawn flat steel resulted in regional failure of the web. To some extent, conventional phenomena such as peeling off surface foamed concrete appeared on the wall. The failure mechanism of the specimen was bending shear failure.

(2) The postcast strip foamed concrete was somewhat separated from the contact with the first casting, but there was no obvious damage to the joint region connecting web and flange by self-tapping screws. The new joint connection method led to an increase in the number of steels at the joint, which played a role equivalent to that of the dark column structure to a certain extent, so that the two walls were formed as a whole, which were not separated with each other during the damage process, with excellent integrity.

(3) Under the condition that the steel content and the density of foamed concrete are fixed, different axial compression ratios have different effects on the 
performance of the wall. On the premise that the axial compression ratio of $\mathrm{T}$-shaped wall is not higher than 0.4 , the shear capacity of the wall can be increased by increasing the axial compression ratio. When the axial compression ratio is higher than 0.4 , the shear capacity of T-shaped wall will weaken to some extent. Therefore, the axial compression ratio should be controlled within 0.4 to ensure the seismic performance of the wall, which is similar to the results of the experiment.

(4) The density of foamed concrete has a certain influence on the seismic performance of the wall. The shear bearing capacity increases with the increase in the density of the foamed concrete. However, due to the brittleness of foamed concrete itself, the growth rate is small, $7.75 \%$, when the difference in densities is not very large.

(5) On the premise that the density of foamed concrete and the axial compression ratio are constant, the space between steels (steel content) and the shear capacity of the wall is in inverse proportion. If the space between steels of the wall is small, the corresponding steel content will be high, the shear capacity will be large, and the seismic performance will be good; on the contrary, if the space between steels of the wall is great, the corresponding steel content will be low, the shear capacity will be small, and the seismic performance will be poor. In general, the space between the steels inside the wall has a greater influence on its seismic performance.

\section{Data Availability}

All data included in this study are available upon request to the corresponding author.

\section{Conflicts of Interest}

The authors declare that they have no conflicts of interest.

\section{Acknowledgments}

This work was supported by the National Natural Science Foundation of China (Grant no. 51378238).

\section{References}

[1] M. Jones and A. Mccarthy, "Utilising unprocessed low-lime coal fly ash in foamed concrete," Fuel, vol. 84, no. 11, pp. 1398-1409, 2005.

[2] E. P. Kearsley and P. J. Wainwright, "The effect of high fly ash content on the compressive strength of foamed concrete," Cement and Concrete Research, vol. 31, no. 1, pp. 105-112, 2001.

[3] E. P. Kearsley and P. J. Wainwright, "Porosity and permeability of foamed concrete," Cement and Concrete Research, vol. 31, no. 5, pp. 805-812, 2001.

[4] C. Fredc, "Rational proportioning of preformed foam cellular concrete," ACI Material Journal, vol. 55, pp. 23-26, 1967.
[5] B. Xia and Dongjun, "Finite element analysis on the lateral resistance of light steel keel composite bearing wall," Building Structure Supplement, vol. 34, p. 8, 2004.

[6] B. Xia, "Research on structural performance of light steel keel composite bearing system," Master's Thesis, Nanjing University of Technology, Nanjing, China, 2003.

[7] H. Ge, Experimental Study and Parameter Optimization Analysis of Steel-Concrete Composite Beam, Xi'an University of Technology, Xi'an, China, 2018.

[8] China Planning Press, Technical Code of Cold-Formed ThinWall Steel structures (GB50018-2002), China Planning Press, Beijing, China, 2002.

[9] Yu. Shi, Study on the Seismic Performance of Multi-Storey Cold-Formed Thin-Walled Steel Structure Houses under Horizontal earthquake, Chang'an University, Xi'an, China, 2008.

[10] L. Shen, Experimental Study on Seismic Performance of T-Shaped Laminated Slab Shear Wall structure, Anhui University of Architecture, Hefei, China, 2010.

[11] C. Gan, Research on Seismic Performance of Built-In Steel Plate Reinforced Concrete Shear Wall, Tongji University, Shanghai, China, 2008.

[12] X. Lv, Y. Dong, and Z. Ding, "Study on seismic performance of concrete shear walls with section steel in the middle section," Earthquake Engineering and Engineering Vibration, vol. 17, no. 6, pp. 101-107, 2006.

[13] X. Zhang, Nonlinear Analysis of Aseismatic Reinforce Concrete structure, Science press, Beijing, China, 2003.

[14] M. Chu, Study on Seismic Performance of Cold-Formed ThinWalled Steel Concrete Shear Wall, Tsinghua University, Beijing, China, 2010.

[15] J. Jiang, Nonlinear Finite Element Analysis of Reinforced Concrete Structures, Shaanxi science \& technology press, Xi'an, China, 1994.

[16] K. Li, Study on Seismic Behavior of Fabricated Steel Foam Concrete T-Shaped Wallborad, Jilin Jianzhu University, Jilin, China, 2019.

[17] L. Manjun, The Value Creation of Assembled Architecture to Urban Ecological Civilization in China, Jiangxi Building Materials, Jiangxi, China, 2018.

[18] Z. B. Meng, Y. Cao, and Y. S. Zhao, "Seismic response analysis for assembled precast concrete residence," Applied Mechanics and Materials, vol. 580-583, pp. 1755-1758, 2014.

[19] W. Wang, A. Li, and X. Wang, "Seismic performance of precast concrete shear wall structure with improved assembly horizontal wall connections," Bulletin of Earthquake Engineering, vol. 2018, Article ID 9632523, 22 pages, 2018.

[20] H. Wu, X. Lu, H. Jiang et al., "Experimental study on seismic performance of prestressed precast concrete shear walls," Jianzhu Jiegou Xuebao/Journal of Building Structures, vol. 37, no. 5, pp. 208-217, 2016. 